This item was submitted to Loughborough's Research Repository by the author.

Items in Figshare are protected by copyright, with all rights reserved, unless otherwise indicated.

\title{
Measurement of vibrational power transmission in curved beams
}

PLEASE CITE THE PUBLISHED VERSION

PUBLISHER

(C) Academic Press / Elsevier

VERSION

AM (Accepted Manuscript)

LICENCE

CC BY-NC-ND 4.0

REPOSITORY RECORD

Walsh, Stephen J., and R.G. White. 2010. "Measurement of Vibrational Power Transmission in Curved Beams". figshare. https://hdl.handle.net/2134/6484. 
MEASUREMENT OF VIBRATIONAL POWER TRANSMISSION IN CURVED BEAMS

S.J. Walsh

Department of Aeronautical and Automotive Engineering

Loughborough University, Loughborough. LE11 3TU. England

and

R.G. White

Department of Aeronautics and Astronautics

University of Southampton, Southampton. SO17 1BJ. England

4 Copies Submitted

34 Manuscript pages

17 Figures

1 Table

RUNNING HEADLINE: Measurement of Vibrational Power Transmission

ADDRESS FOR CORRESPONDENCE:

Dr S.J. Walsh

Department of Aeronautical and Automotive Engineering

Loughborough University

Loughborough, LE11 3TU. UK 


\begin{abstract}
Previous research into structural vibration transmission paths has shown that it is possible to t. measure vibrational power transmission in simple beam and plate structures. However, in many practical structures transmission paths are composed of more complex, curved elements, therefore there is a need to extend vibrational power transmission analyses to this class structure. In a companion publication [1] expressions were derived which described vibrational power transmission due to predominantly flexural, extensional and shear types of travelling wave in a curved beam where the neutral axis forms a plane curve of constant radius of curvature. In this paper a strategy to measure vibrational power transmission in a curved beam is developed and applied to an experimental mild steel beam. The experimental apparatus is described and the measurement method outlined. Results of experimental measurements of the vibrational power transmitted along the beam are presented and compared to corresponding values of the power input to the structure.
\end{abstract}




\section{INTRODUCTION}

"Power flow" may be defined as the vibrational power per unit width of cross-section [2]. It is a technique which enables power input to structures from a source via all degrees of freedom and through a variety of paths to be assessed and ranked in order of importance. Power transmission through a range of structural components by a variety of wave types can also be examined in order to determine the dominant propagation mechanisms. For example, it is impossible to compare translational and rotational transfer functions because of conflicting units. However, the associated vibrational power transmission terms can be compared directly. Thus the main advantages of a vibrational power transmission approach are: (i) being a vector quantity (magnitude and direction), power flow is a familiar concept with a clear physical interpretation; (ii) vibrational power transmission techniques can be used to locate and assess the strength and direction of sources and subsequent transmission paths.

Previous research into structural transmission paths has shown it is possible to measure vibrational power transmission in simple beam and plate structures. More recently, transmission through pipes with bends, branches and discontinuities has been studied [3], which has led to useful design rules concerning the position and size of pipe supports for minimum power transmission. However, industrial applications have had a slower development than the corresponding acoustic intensity methods. One of the reasons for the lack of acceptance of such techniques is the difficulty of measurement in practical situations, for example, where the structural transmission paths are through more complex elements such as curved pipework.

In this paper the results of experimental studies of vibrational power transmission along a curved mild steel beam are reported where the centre-line of the beam forms a plane curve of constant radius of curvature. In a straight beam, flexural and extensional wave motions are uncoupled. For a curved beam, however, there is interaction between the lateral and longitudinal deformations leading to coupled lateral-longitudinal propagation. A companion publication [1] contained an analysis of four different theories of wave motion in a curved beam. Two can be classed as "simple bending" theories and include extension of the centre-line during flexural deformation. The first was based upon a reduction of Love's thin shell equations and the second was based upon a similar reduction of Flügge's thin shell equations. The third theory included a correction for rotary inertia and the fourth an additional correction for shear deformation. For each of the four different theories, expressions were derived which described the vibrational power 
transmission due to flexural, extensional and shear types of travelling wave in the beam. By assuming sinusoidal wave motion, expressions were developed which related the time-averaged power transmission to the travelling wave amplitudes. The results of numerical studies were presented which showed that rotary inertia and shear deformation effects are only important when the wavelength approaches the thickness of the beam. Thus, at lower frequencies the "simple bending" based equations provide an adequate description of the vibrational power transmission. However, the vibrational power transmission equations with the simplest form were those derived using the Flügge based theory. Hence, in section 2 of this paper finite difference approximations are applied to the Flügge based expressions presented in reference [1] to produce a strategy to measure the vibrational power transmitted along a curved beam. In section 3 the experimental apparatus used to measure transmitted power is described and the measurement method outlined. In section 4 the results of transmitted power measurements are presented and compared with corresponding measurements of power input to the structure.

\section{THEORY OF VIBRATIONAL POWER TRANSMISSION ALONG A BEAM WITH CONSTANT CURVATURE}

Using the Flügge based expressions for stresses and displacements in a beam with constant curvature, equations for vibrational power transmission were derived in reference [1]. For a changing curvature beam, the radius of curvature, $\mathrm{R}$, is no longer a constant but is a variable dependent upon the circumferential distance, s. This more complex type of structural element is not considered in this publication. It is also assumed in this study that internal dissipation within the beam is negligible. Thus, an entirely real Young's modulus, E, is introduced. By analogy to vibrational power transmission in a straight beam, the equations in reference [1] were expressed in terms of an extensional component, $\mathrm{P}_{\mathrm{e}}$, a bending moment component, $\mathrm{Pbm}$, and a shear force

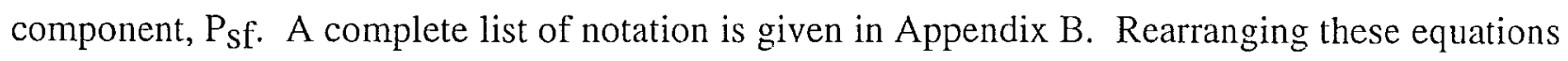
enables "straight" beam and "curved" beam power components to be identified. The "curved" beam terms are those that include the radius of curvature, $R$, and the "straight" beam terms are the corresponding expressions for purely extensional or purely flexural waves in a straight rod or beam. Thus, 


$$
\begin{aligned}
& \mathrm{P}_{\mathrm{e}}=\underbrace{-\mathrm{ES} \frac{\partial \mathrm{u}}{\partial \mathrm{s}} \frac{\partial \mathrm{u}}{\partial \mathrm{t}}}_{\text {straight }} \underbrace{\mathrm{ES} \frac{\mathrm{w}}{\mathrm{R}} \frac{\partial \mathrm{u}}{\partial \mathrm{t}}}_{\text {curved }}, \\
& \text {, } \\
& \mathrm{P}_{\mathrm{bm}}=\underbrace{\mathrm{EI} \frac{\partial^{2} \mathrm{w}}{\partial \mathrm{s}^{2}} \frac{\partial}{\partial t}\left(-\frac{\partial \mathrm{w}}{\partial \mathrm{s}}\right)}_{\text {straight }}+\underbrace{\mathrm{EI} \frac{\mathrm{w}}{\mathrm{R}^{2}} \frac{\partial}{\partial t}\left(-\frac{\partial \mathrm{w}}{\partial \mathrm{s}}\right)}_{\text {curved }}, \\
& \mathrm{P}_{\mathrm{sf}}=\underbrace{\mathrm{EI} \frac{\partial^{3 / 3} \mathrm{w}}{\partial \mathrm{s}^{3}} \frac{\partial \mathrm{w}}{\partial \mathrm{t}}}_{\text {straight }} \underbrace{\mathrm{EI} \frac{1}{\mathrm{R}^{2}} \frac{\partial \mathrm{w}}{\partial \mathrm{s}} \frac{\partial \mathrm{w}}{\partial \mathrm{t}}}_{\text {curved }},
\end{aligned}
$$

where $u(s, t)$ and $w(s, t)$ are the longitudinal and lateral displacements of a wave travelling in the circumferential direction along the beam as shown in Figure 1. Equations (1), (2) and (3) contain spatial and temporal derivatives of the longitudinal displacement, $u(s, t)$ and the lateral displacement, $w(s, t)$. The temporal derivatives can be evaluated directly from measured acceleration signals, whilst the spatial derivatives can be estimated using finite difference approximations.

To apply finite difference approximations to the lateral accelerations, $a_{w}$, consider an array of four accelerometer locations, $s_{1}, s_{2}, s_{3}$ and $s_{4}$ each separated by a distance, $\Delta_{\mathrm{f}}$, and surrounding the measurement position, $\mathrm{s}_{\mathrm{o}}$, as shown in Figure 2 . Then, by applying finite difference approximations [4] the acceleration, $\mathrm{a}_{\mathrm{w}}$, at $\mathrm{s}_{\mathrm{O}}$ is given by

$$
\mathrm{a}_{\mathrm{w}}=\frac{1}{2}\left[\mathrm{a}_{2}+\mathrm{a}_{3}\right]
$$

Similarly the first spatial derivative is given by

$$
\frac{\partial \mathrm{a}_{\mathrm{w}}}{\partial \mathrm{s}}=\frac{\mathrm{a}_{3}-\mathrm{a}_{2}}{\Delta_{\mathrm{f}}}
$$

the second spatial derivative by 


$$
\frac{\partial^{2} \mathrm{a}_{\mathrm{w}}}{\partial \mathrm{s}^{2}}=\frac{1}{2} \frac{\left[\mathrm{a}_{1}-\mathrm{a}_{2}-\mathrm{a}_{3}+\mathrm{a}_{4}\right]}{\Delta_{\mathrm{f}}^{2}},
$$

and the third spatial derivative by

$$
\frac{\partial^{3} a_{w}}{\partial s^{3}}=\frac{\left[a_{4}-3 a_{3}+3 a_{2}-a_{1}\right]}{\Delta_{f}^{3}}
$$

The corresponding finite difference approximations for the longitudinal acceleration, $a_{\mathfrak{u}}$, and its first spatial derivative are given by

$$
\begin{aligned}
& \mathrm{a}_{\mathrm{u}}=\frac{1}{2}\left[\mathrm{a}_{\mathrm{u}_{2}}+\mathrm{a}_{\mathrm{u}_{3}}\right], \\
& \frac{\partial \mathrm{a}_{\mathrm{u}}}{\partial \mathrm{s}}=\frac{\mathrm{a}_{\mathrm{u}_{3}}-\mathrm{a}_{\mathrm{u}_{2}}}{\Delta_{\mathrm{u}}},
\end{aligned}
$$

where $\mathrm{a}_{\mathrm{u}_{2}}$ and $\mathrm{a}_{\mathrm{u}_{3}}$ represent acceleration signals from an array of two accelerometers at positions $\mathrm{s}_{\mathrm{u}_{2}}$ and $\mathrm{s}_{\mathrm{u}_{3}}$ as shown in Figure 3. Substituting the finite difference approximations, equations (4) - (9), into equations (1) - (3) gives the following expressions for instantaneous vibrational power transmission in terms of the acceleration signals, $a_{1}, a_{2}, a_{3}, a_{4}, a_{\mathbf{u}_{2}}$ and $a_{\mathbf{u}_{3}}$.

Expressions for time averaged power can be obtained by applying the following relationships between the time averaged product of the displacement and velocity of two sinusoidal signals [5]:

$$
\left\langle w_{1}(t) \cdot w_{2}(t)\right\rangle_{t}=-\left\langle w_{2}(t) \cdot w_{1}(t)\right\rangle_{t},
$$

which in terms of acceleration signals, $a_{j}$, becomes

$$
\left\langle\iint a_{1} d t d t \int a_{2} d t\right\rangle_{t}=-\left\langle\iint a_{2} d t d t \int a_{1} d t\right\rangle_{t}
$$


The following relationship given in reference [6] enables the time averaged product of velocity and displacement signals to be expressed in the frequency domain in terms of the imaginary part of the single sided cross spectral deńsity function, $G(f)$ :

$$
\left\langle\int a_{1} d t \iint a_{2} d t d t\right\rangle_{t}=\frac{1}{(2 \pi f)^{3}} \int_{0}^{\infty} \operatorname{Im}\left\{G\left(a_{1}, a_{2}\right)\right\} d f
$$

Thus, the combined "straight" bending moment and shear force components can be expressed in the frequency domain as

$$
\begin{aligned}
& \left\langle\left(\mathrm{P}_{\mathrm{bm}}+\mathrm{P}_{\mathrm{sf}}\right)(\text { straight })\right\rangle_{\mathrm{t}}= \\
& \frac{\mathrm{EI}}{\Delta_{\mathrm{f}}^{3}(2 \pi \mathrm{f})^{3}}\left[-\int_{0}^{\infty} \operatorname{Im}\left\{\mathrm{G}\left(\mathrm{a}_{1}, \mathrm{a}_{3}\right)\right\} \mathrm{df}\right. \\
& +4 \int_{0}^{\infty} \operatorname{Im}\left\{\mathrm{G}\left(\mathrm{a}_{2}, \mathrm{a}_{3}\right)\right\} \mathrm{df} \\
& \left.+\int_{0}^{\infty} \operatorname{Im}\left\{\mathrm{G}\left(\mathrm{a}_{4}, \mathrm{a}_{2}\right)\right\} \mathrm{df}\right],
\end{aligned}
$$

and the combined "curved" bending moment and shear force components can be expressed as

$$
\begin{array}{r}
\left\langle\left(P_{b m}+P_{\text {sf }}\right)(\text { curved })\right\rangle_{t}= \\
\frac{-2 E I}{\Delta_{\mathrm{f}} \mathrm{R}^{2}(2 \pi f)^{3}} \int_{0}^{\infty} \operatorname{Im}\left\{G\left(a_{2}, a_{3}\right)\right\} d f
\end{array}
$$

Similarly, the "straight" extensional component can be expressed as

$$
\begin{gathered}
\left\langle\mathrm{P}_{\mathrm{e}}(\text { straight })\right\rangle_{\mathrm{t}}= \\
\frac{\mathrm{ES}}{\Delta_{\mathrm{u}}(2 \pi \mathrm{f})^{3}} \int_{0}^{\infty} \operatorname{Im}\left\{\mathrm{G}\left(\mathrm{a}_{\mathrm{u}_{2}}, \mathrm{a}_{\mathrm{u}_{3}}\right)\right\} \mathrm{df},
\end{gathered}
$$

and the "curved" extensional component can be expressed as 


$$
\begin{gathered}
\left\langle\mathrm{P}_{\mathrm{e}} \text { (curved) }\right\rangle_{\mathrm{t}}= \\
\frac{-\mathrm{ES}}{4 \mathrm{R}(2 \pi \mathrm{f})^{3}}\left[\int_{0}^{\infty} \operatorname{Im}\left\{\mathrm{G}\left(\mathrm{a}_{2}, \mathrm{a}_{\mathrm{u}_{2}}\right)\right\} \mathrm{df}\right. \\
+\int_{0}^{\infty} \operatorname{Im}\left\{\mathrm{G}\left(\mathrm{a}_{2}, \mathrm{a}_{\mathrm{u}_{3}}\right)\right\} \mathrm{df} \\
+\int_{0}^{\infty} \operatorname{Im}\left\{\mathrm{G}\left(\mathrm{a}_{3}, \mathrm{a}_{\mathrm{u}_{2}}\right)\right\} \mathrm{df} \\
\left.+\int_{0}^{\infty} \operatorname{Im}\left\{\mathrm{G}\left(\mathrm{a}_{3}, \mathrm{a}_{\mathrm{u}_{3}}\right)\right\} \mathrm{df}\right]
\end{gathered}
$$

Equations (13) - (16) represent a set of four equations to which enable measurements of transmitted power in a curved beam to be made using an array of six accelerometers. The values $a_{1}, a_{2}, a_{3}, a_{4}$ represent signals from an array of four accelerometers mounted in the radial direction and $\mathrm{a}_{\mathrm{u} 1}$ and $\mathrm{a}_{\mathrm{u} 2}$ represent those from two accelerometers mounted in the circumferential direction. For convenience the time averaged sum of the "straight" bending moment and shear force component, equation (13), will be referred to as the "flexural straight" component. This "flexural straight" component, equation (13), is identical to the traditional four accelerometer "near field" expression used to measure vibrational power transmission due to purely flexural waves in a straight beam [6]. The time averaged sum of the "curved" bending moment and shear component, equation (14), will be referred to as the "flexural curved" component. Likewise, the time averaged "straight" extensional component, equation (15), will be referred to as the "extensional straight" component. This "extensional straight" component is identical to the expression used to measure vibrational power transmission due to purely longitudinal waves in a straight bar [6]. The final component, the time averaged "curved" extensional component, equation (16), will be referred to as the "extensional curved" component.

The power input to the beam can be calculated from the real part of the point mobility of the structure [7]. Thus,

$$
P_{\text {in }}(f)=G_{F F}(f) \operatorname{Re}\{Y(f)\}
$$


where $G_{F F}(f)$ is the auto spectral density function of the applied force and $Y(f)$ is the point mobility. Alternatively, the, value of the power input to the structure can be calculated directly from the cross spectral density function between the force and response velocity signals:

$$
P_{\text {in }}(f)=\operatorname{Re}\left\{G_{F V}(f)\right\} \text {. }
$$

\section{EXPERIMENTAL APPARATUS AND METHOD}

Measurements of transmitted power were made on the experimental curved beam shown schematically in Figure 4. It was noted in references [1] and [8] that for a beam with constant curvature the ring frequency, $\Omega=1$, is of great significance since at this frequency there is a change in wave types. Above the ring frequency three wave types are possible: 1) a predominantly flexural travelling wave; 2) a predominantly flexural near field wave; and 3) a predominantly extensional travelling wave. Below the ring frequency the predominantly flexural travelling and near field waves still exist. However, the predominantly extensional wave is now of a near field type. Thus, it was decided to take measurements of transmitted power on an experimental beam with a significant measurable frequency range both above and below the ring frequency. Apart from the addition of a small aluminium block at a position $0.6 \mathrm{~m}$ from the free end of the beam, this is the same experimental apparatus as used in the study of point mobility characteristics reported in reference [8]. The beam was made of mild steel. It was $5 \mathrm{~m}$ long and had a width of $50 \mathrm{~mm}$. The thickness of the beam was measured with a micrometer at six different locations along its length and average of these readings was found to be $6.07 \mathrm{~mm}$. The beam had a constant radius of curvature of $1.0 \mathrm{~m}$, thus, the ring frequency $\Omega=1$ occurred at $817 \mathrm{~Hz}$. The dimensions and material properties of the experimental beam are listed in Table 1. Figure 4 shows a schematic representation of the experimental apparatus. To obtain free conditions at the end of the beam, the whole beam was suspended on thin wires at $1 \mathrm{~m}$ intervals from underneath laboratory benches. It was assumed that no motion would occur in the plane of the suspension system.

To obtain "semi-infinite" conditions one end of the beam was inserted into an anechoic termination. This termination consisted of a $1 \mathrm{~m}$ long box filled with sand to dissipate the energy of the wave motion. To attenuate lateral displacements, foam wedges were inserted into the 
corners of the box to create a large triangular region of sand. For lateral displacements this termination will be effective when the length of the beam within the box is greater than one half of the wavelength of the waves travelling in the beam. For purely flexural waves in a straight EulerBernoulli beam of the same dimensions this would occur at $13 \mathrm{~Hz}$. For the experimental curved beam, it was assumed that this will occur at approximately the same frequency. To attenuate longitudinal displacements, forty thin aluminium alloy strips of various lengths $(50-100 \mathrm{~mm})$ were attached at right angles to that portion of the beam which lay in the sand box. Further details of the design of the anechoic termination are given in reference [9], although specific measurements of the reflection properties of the termination were not undertaken.

The excitation force was obtained by striking the beam with an instrumented hammer (BK8202). A series of tests was conducted using four excitation positions: (i) excitation in the circumferential direction at the free end; (ii) excitation in the radial direction at the free end; (iii) excitation in the circumferential direction at a point $0.6 \mathrm{~m}$ from the free end; and (iv) excitation in the radial direction at a point $0.6 \mathrm{~m}$ from the free end. To assist in obtaining a purely circumferential force at the free end a steel triangular block was glued at the centre of the crosssection of the end of the beam. Circumferential excitation at a position along the beam was attempted by striking a similar triangular block glued to the top of the beam. When exciting the beam in the radial direction care was taken to strike the centre-line of the beam. The applied force was measured with the instrumented hammer, whilst the response acceleration was measured using two 11 gram accelerometers (BK4371). At the free end of the beam longitudinal acceleration was measured using an accelerometer mounted on the cross-section of the beam just above the triangular block. Lateral acceleration was measured using an accelerometer, mounted on the centre-line of the side of the beam.

When exciting the beam at a point $0.6 \mathrm{~m}$ from the free end of the beam the response was measured using a different configuration of accelerometers depending upon whether the beam was excited in the circumferential or radial direction. In both cases lateral acceleration was measured using a 17 gram BK4383 accelerometer mounted in the radial direction on the centre-line of the beam. For radial excitation of the beam, longitudinal acceleration was measured using an 11 gram BK4371 accelerometer mounted onto the rear of the triangular block. For circumferential excitation, the longitudinal acceleration was measured using a 0.65 gram BK4374 accelerometer mounted onto the centre-line of the beam in the circumferential direction. Although the 0.65 gram accelerometer has less dynamic range than the 17 gram accelerometer, its low weight enabled it to 
be glued directly onto the side of the beam in the circumferential direction. The applied force and resulting accelerations were recorded simultaneously on an HP3566A spectrum analyser. The point and cross mobilities were calculated directly from a single measurement by dividing the response velocities by the applied force. For the case of circumferential excitation at a point $0.6 \mathrm{~m}$ from the free end the signal to noise ratio of the mobility data was improved by forming an average of four separate measurements.

The transmitted power was measured at a point, $\mathrm{s}_{\mathrm{o}}$, approximately $2 \mathrm{~m}$ from the free end of the beam using an array of six accelerometers. The time averaged bending moment and shear force component, equations (13) and (14), was measured using the four radially mounted accelerometers and the time averaged extensional component measured using the two circumferentially mounted accelerometers plus two radially mounted accelerometers. A schematic representation of the transducer configuration is shown in Figure 5. To minimise finite difference and phase mis-match errors the accelerometers were spaced 0.2 of a wave length apart [10]. For radial excitation of the beam it was assumed that the majority of the beam displacement would be due to the predominantly flexural waves. Thus, to measure the bending moment and shear force components of transmitted power, equations (13) and (14), the radially mounted accelerometers, $a_{1}, a_{2}, a_{3}$, and $\mathrm{a}_{4}$, were positioned $10 \mathrm{~cm}$ apart. Similarly, for circumferential excitation of the beam it was assumed that the majority of the beam displacement would be due to predominantly extensional waves. Thus, to measure the extensional components of transmitted power, equations (15) and (16), the circumferentially mounted accelerometers, $\mathrm{a}_{\mathrm{u} 1}$ and $\mathrm{a}_{\mathrm{u} 2}$, were positioned $1 \mathrm{~m}$ apart. Ideally, additional radially mounted accelerometers positioned $1 \mathrm{~m}$ apart would be used to measure the radial accelerometer signals, a2, a3, in the "curved" extensional component, equation (16). However, the spectrum analyser was limited to eight simultaneous measurement channels and, thus, the existing radially mounted accelerometers, positioned $10 \mathrm{~cm}$ apart, were used to measure the "curved" extensional component.

When considering purely extensional waves in a straight bar there will also be a deformation of the cross-section in the lateral direction due to Poisson's ratio. An analysis of the magnitude of this effect is presented in reference [11], where it is shown that the ratio of the greatest lateral displacement to the greatest longitudinal displacement is approximately equal to the ratio of the thickness of the beam to the extensional wavelength. For the frequency range considered in the current curved beam study this ratio is small. Hence, the effect of Poisson's ratio on lateral and longitudinal displacements has been neglected. 


\section{DISCUSSION OF RESULTS \\ 4.1 CIRCUMFERENTIAL EXCITATION AT THE FREE END}

Structural testing consisted of two stages: first the power input to the beam per unit force was calculated from measurements of the point mobility of the beam using a re-arranged equation (17). These data were then compared with predictions of the real part of the point mobility calculated from the theoretical models also described in Appendix A. In the second stage of the test a value of total power input to the beam was calculated using equation (18). Strictly, the term "power" should only be applied to a system under continuous excitation, whereas, for the following experiments transient energy flow and not power was measured. However, to convert from a quantity in units of energy to a quantity in units of power the total energy of the signal should be divided by its duration. In all the following cases the duration of the data acquisition was one second, therefore, for convenience, units of power have been retained.

The results of the first stage of the test are shown in Figure 6 which shows measured and predicted values of the real part of the point mobility of the beam when excited circumferentially at the free end. The frequency range is expressed in terms of the non-dimensional frequency $\Omega=\frac{\omega R}{c_{0}}$, where $c_{o}$ is the phase velocity of purely extensional waves in a straight bar. The frequency axis extends over the non-dimensional frequency range $\Omega=0.1$ to $\Omega=10.0$ which for the experimental beam represents a dimensional frequency range of $83 \mathrm{~Hz}$ to $8.2 \mathrm{kHz}$. It can be seen that below the ring frequency, $\Omega=1$, the predicted values of the real part of the point mobility are zero and, hence, indicate that no power should be input to the structure. This is consistent with previous studies, $[1,8]$, which show that below the ring frequency only predominantly extensional near field waves are to be expected. However, the measured data indicate that some power was input to the beam below the ring frequency. One explanation for this discrepancy is obtained by considering the wavelength of predominantly extensional near-field waves. At these low frequencies the near-field wavelength is greater than the length of the experimental beam. Thus, power is being transmitted not by travelling waves but by near-field waves. Above the ring frequency Figure 6 indicates maxima in the input power data at $\Omega=1.6,2.0$ and 2.8. These frequencies correspond approximately to the natural frequencies of a straight free-free rod of the 
same dimensions and material properties as the experimental curved beam. Thus, the maxima in Figure 6 are associated with the reflection of predominantly extensional travelling waves in the beam. As expected the predicted value of the input power lies between the peaks and troughs of the measured data. Above $\Omega=3.0$ the measured data indicate poor signal to noise ratio due to the upper frequency limit of the applied force.

The results of the second stage of the test, a comparison between the input and transmitted power, is shown in Figure 7. Figure 7(a) shows the power input to the beam calculated from equation (18). Comparing this figure with Figure 6, the real part of the point mobility (or power input per unit force), it can be seen that there are differences between the spectra above the ring frequency. This is due to the characteristics of the excitation force which had a flat energy spectrum up to $\Omega=1.5$ but thereafter decayed, becoming zero at $\Omega=3.0$. At low frequencies, below $\Omega=0.2$, the input power data shown in Figure 7(a) are negative. This is physically impossible and is likely to be an error caused by measuring below the lower frequency limit of themeasurement system.

The total power transmitted along the beam is shown in Figure 7(b). This is calculated by adding together the "extensional straight", "extensional curved", "flexural straight" and "flexural curved" components. It can be seen that above the ring frequency significant transmitted power is indicated at frequencies $\Omega=1.6$ and 2.0 associated with the extensional resonances of the beam. Below the ring frequency the measured transmitted power data indicate significant fluctuations in amplitude, including at some frequencies the physically impossible situation of negative transmitted power. These fluctuations in amplitude increase as the frequency decreases. There are a number of factors which may give rise to errors in the measurement of transmitted power. These include: accelerometer cross-sensitivity; amplitude and phase mis-match between transducers; and imperfect transducer positioning. All of these factors may have contributed to the difficulty in obtaining reliable results below the ring frequency.

An analysis of individual transmitted power components is shown in Figures 7(c) to 7(e). Figure 7(c) shows the "straight" extensional component calculated using equation (15). It can be seen that above the ring frequency transmitted power has been measured with the amplitude of this component being approximately $2 / 3$ of the amplitude of the total transmitted power shown in Figure 7(b). Immediately below the ring frequency this component is approximately zero, whilst below $\Omega$ 
$=0.4$ the measured signal is in error due to the limitations of the measurement system. Figure 7(d) shows the extensional "curved" component calculated using equation (16). Above the ring frequency transmitted power has been successfully measured, although compared with the extensional "straight" component the spectra show much greater amplitudes close to the ring frequency. An explanation for this lies in the nature of the wave motion just above the ring frequency. In reference [1] it was shown that predominantly extensional waves consist of coupled lateral-longitudinal displacements, with the ratio of the lateral to longitudinal displacement being

determined by the frequency range. Close to the ring frequency the predominantly extensional wave contains significant lateral displacement although this is rapidly dominated by the longitudinal displacement as the frequency increases. Thus, the "curved" extensional component which is measured using both circumferentially and radially mounted accelerometers, will record this coupled wave motion. It can be seen in Figure 7 (d) that below the ring frequency the measured signal is corrupted by the limitations of the measurement system. Figure 7(e) shows the "straight" flexural component calculated using equation (13). It can be seen that power was transmitted at frequencies corresponding approximately to resonances associated with the reflection of predominantly flexural waves due to the finite length of the "semi-infinite" beam. This may have been due to a slightly off-axis excitation force being applied to the beam, thus giving rise directly to predominantly flexural wave motion. The "curved" flexural component was calculated using equation (14) which for this measurement was negligible and has not been shown. Inspection of the coefficients in equation (14) shows that this is likely to be the case for most situations. For example, given an accelerometer spacing, $\Delta_{\mathrm{f}}$, of $10 \mathrm{~cm}$ and a radius of curvature, $\mathrm{R}$, of $1.0 \mathrm{~m}$, the coefficient, $\frac{-2 \mathrm{EI}}{\mathrm{R}^{2} \Delta_{\mathrm{f}} \omega^{3}}$, in equation (14) is only $2 \%$ of the value of the coefficient, $\frac{-4 \mathrm{EI}}{\Delta_{\mathrm{f}}^{3} \omega^{3}}$, in the corresponding "a $2-\mathrm{a}_{3}$ " term in equation (13).

\subsection{RADIAL EXCITATION AT THE FREE END}

A comparison of the measured and predicted values of the real part of the point mobility of the experimental beam when excited in the radial direction at the free end is shown in Figure 8. It can be seen from the measured data that power was input at frequencies corresponding approximately to resonances associated with the reflection of predominantly flexural waves due to the finite length of the experimental "semi-infinite" beam. As expected, the predicted values, which model a 
true "semi-infinite" beam, lie between the peaks and troughs of experimental data. It is also apparent that the ring frequency had no significance for radial excitation of the beam. Thus, for radial excitation at the free, end the experimental curved beam responded as if it were a straight beam.

A comparison of the measured input and transmitted powers is shown in Figure 9. Figure 9(a) shows the power input to the beam calculated from equation (18). Figure 9(b) shows the "straight" flexural component, equation (13), which indicates that transmitted power is being measured at identical frequencies to the input power data shown in Figure 9(a). However, the amplitudes of the transmitted power data are slightly less that the corresponding amplitudes of the input power data. In the previous section it was noted that the "curved" flexural component, equation (14), is likely to be negligible in comparison with the "straight" flexural component. This is also the case for radial excitation of the beam and, hence, this component has not been shown. Figures $9(\mathrm{c})$ and 9(d) show the "straight" extensional and "curved" extensional components, respectively. It can be seen that above the ring frequency, $\Omega=1.0$, no transmitted power has been detected. Below the ring frequency the data are in error due to the limitations in the measurement system. The total transmitted power should be calculated by adding together all the transmitted power components. However, this value was distorted by the erroneous data in the extensional power components. Thus, for radial excitation at the free end the most accurate measurement of transmitted power was obtained by using the "straight" flexural component only and disregarding the "straight" extensional and "curved" extensional components.

\subsection{CIRCUMFERENTIAL EXCITATION AT A POINT 0.6 M FROM THE FREE END}

A comparison of the measured and predicted values of the real part of the point mobility of the experimental beam when excited circumferentially at a point $0.6 \mathrm{~m}$ from the free end is shown in Figure 10. Above the ring frequency the measured and predicted data indicate a maxima in the input power at a frequency $\Omega=1.6$ associated with the reflection of predominantly travelling extensional waves from the free end of the beam. Below the ring frequency both the measured and predicted data indicate that power was input to the beam, with resonant effects associated with the reflection of near field waves from the free end.

A comparison of the measured input and transmitted powers is shown in Figure 11. Figure 11(a) shows the power input to the beam calculated using equation (18). Above the ring frequency 
power was input to the structure in the frequency region $\Omega=1.0$ to 2.0 . However, below the ring frequency although some input power was to be expected, the data show only measurement noise. The total power transmitted along the beam is shown in Figure 11(b). This was calculated by adding together the "straight" extensional, and "curved" extensional components. It can be seen that above the ring frequency the transmitted power spectra reflects closely the input power spectra shown in Figure 11(a). However, below the ring frequency the transmitted power data are corrupted by the limitations of the measurement system and, hence, do not reliably indicate any transmitted power.

In Figures 11(c) to 11(e) the total transmitted power is separated into its three components. Figure 11(c) shows the "straight" extensional component where it can be seen that above the ring frequency transmitted power has been measured, the amplitude of this component being greatest at $\Omega=1.6$. Below the ring frequency the "straight" extensional component is dominated by measurement noise. Figure 11(d) shows the "curved" extensional component. Above the ring frequency, transmitted power has been successfully measured with the peak of the spectra, at $\Omega=$ 1.2, being much closer to the ring frequency than the "straight" extensional component. Figure 11(e) shows the straight flexural component which was negligible above the ring frequency and in error due to limitations in the measurement system below the ring frequency. Hence, the "straight" flexural component was not included in the summation for total transmitted power shown in Figure 11(b). The "curved" extensional component was negligible and was not included in the summation.

\subsection{RADIAL EXCITATION AT A POINT 0.6 M FROM THE FREE END}

A comparison of the measured and predicted values of the real part of the point mobility of the experimental beam when excited radially at a point $0.6 \mathrm{~m}$ from the free end is shown in Figure 12 . The measured data indicate that power was input at frequencies associated with the reflection of predominantly flexural waves in the beam. However, in contrast to radial excitation at the free end, as shown in Figure 8, the point mobility due to radial excitation at a point along the beam, shown in Figure 12, exhibits broad maxima and minima due to waves reflected from the free end. It is also apparent that the ring frequency has no significance. 
A comparison of the measured input and transmitted powers is shown in Figure 13. Figure 13(a) shows the power input to the beam calculated using equation (18). Figure 13(b) shows the "straight" flexural component" which indicates that transmitted power was measured at frequencies corresponding to the input power data shown in Figure 13(a). As expected, the amplitudes of the transmitted power data are slightly lower than the corresponding amplitudes of the input power data. The "curved" flexural component was negligible and has not been shown. Figures 13(c) and 13(d) show the "straight" extensional and "curved" extensional components, respectively. For both components no transmitted has been measured above $\Omega=0.5$, whilst below this frequency distortions in the measurements due to the limitations of the measurement system are apparent. In principle, the total transmitted power should be calculated by adding together all the transmitted power components. However, this value was distorted due to the errors in the extensional power components. Thus, the measurement of transmitted power was made using the "straight" flexural component only, and the "straight" extensional and "curved" extensional components were discarded.

\section{SUMMARY OF FINDINGS}

This paper has reported measurements of the power transmitted along an experimental "semiinfinite" beam with a constant radius of curvature. Previously derived equations for vibrational power transmission in a curved beam were introduced which by analogy with power transmission in a straight beam, were represented in terms of extensional, bending moment and shear force components. These equations have been reformulated in terms of "straight" beam and "curved" beam components and by using finite difference approximations a measurement strategy has been devised. Analysis of the transmitted power data in terms of these "straight" and "curved" components leads to the following findings which depend upon the excitation location and direction.

When exciting the beam circumferentially at the free end, the ring frequency had great significance. Above the ring frequency, $\Omega=1.0$, measurements of transmitted power were made by summing the "straight" extensional and "curved" extensional components, equations (15) and (16). The "straight" flexural component, equation (13), was useful in detecting off-axis excitation, but for purely circumferential excitation was disregarded. Below the ring frequency measurements 
of transmitted power were limited by the accuracy of the measurement system and good experimental results were difficult to obtain. Over the entire frequency range the "curved" flexural component, equation (14)," was negligible in comparison to the other transmitted power components and was neglected.

When exciting the beam circumferentially at a point away from the free end, the frequency response of the curved beam was divided into two regions separated by the ring frequency. Above the ring frequency power was input to the beam and transmitted by a predominantly extensional travelling wave. Hence, measurements of transmitted power were made by summing the "straight" extensional and "curved" extensional components. Below the ring frequency the real part of the point mobility indicated that power was input to the beam. This was probably due to the interaction of the predominantly extensional near field wave with the free end of the beam. Hence, in principle, measurements of transmitted power should be made by summing the "straight" extensional and "curved" extensional components. Unfortunately, the measured data were corrupted by noise in the measurement system and, hence, did not reliably indicate any transmitted power.

When exciting the beam in the radial direction, whether at the free end or at any point away from the free end, the curved beam responded as if it were straight. Thus, power was input to the structure and was transmitted by predominantly flexural travelling waves. Hence, measurements of transmitted power should be made by summing the "straight" flexural and "curved" flexural components. However, the "curved" flexural component was small in comparison to the "straight" flexural component and, thus, neglected. The "straight" extensional component and "curved" extensional component were both in error due to limitations in the measurement system and, thus, were disregarded.

\section{CONCLUSIONS}

Given the findings noted in section 5, the following conclusions can be drawn regarding the measurement of vibrational power transmission in curved beams.

1) For radial excitation, when predominantly flexural waves are the main energy carrying mechanism, then the traditional four accelerometer technique used to measure vibrational power transmission due to purely flexural waves in a straight beam should be used. 
2) For circumferential excitation, when predominantly extensional waves are the main energy carrying mechanism, then measurements of transmitted power should be made by summing the "straight" extensional and "cúrved" extensional components. However, below the ring frequency the method is limited,by the accuracy of the measurement system and reliable measurements of transmitted power were not obtained.

\section{ACKNOWLEDGMENTS}

The experimental work presented in this paper was carried out while both authors were at the Institute of Sound and Vibration Research, University of Southampton. The financial support of the Marine Technology Directorate Limited is gratefully acknowledged. 


\section{REFERENCES}

1. S. J. WALSH and R. G. WHITE 2000 Provisionally scheduled for publication in the Journal of Sound and Vibration June, 2000. Vibrational power transmission in curved beams.

2. D. U. NOISEUX 1970 Journal of the Acoustical Society of America 47, 238247. Measurément of power flow in uniform beams and plates.

3. J. L. HORNER and R. G. WHITE 1991 Journal of Sound and Vibration 141, 87-103. Prediction of vibrational power transmission through bends and joints in beam-like structures.

4. A. JEFFREY 1979 Mathematics for engineers and scientists. Walton-onThames, Surrey: Thomas Nelson and Sons.

5. G. PAVIC 1976 Ph.D. Thesis, University of Southampton. Techniques for the determination of vibration transmission mechanisms in structures.

6. J. W. VERHEIJ 1980. Journal of Sound and Vibration 70, 133-139. Cross spectral density techniques for measuring structure borne power flow on beams and pipes.

7. R. J. PINNINGTON and R. G. WHITE 1981 Joumal of Sound and Vibration $75,179-197$. Power flow through machine isolators to resonant and nonresonant beams.

8. S. J. WALSH and R. G. WHITE 1999 Journal of Sound and Vibration 221, 887-902. Mobility of a semi-infinite beam with constant curvature.

9. $\quad$ S. J. Walsh 1996 Ph.D. Thesis, University of Southampton. Vibrational power transmission in curved and stiffened structures.

10. W. REDMAN-WHITE 1984 Proceedings of the Second International Conference on Recent Advances in Structural Dynamics, 467-474. The experimental measurement of flexural wave power in structures.

11. L. CREMER, M. HECKL and E. E. UNGAR 1973 Structure-Bome Sound. Berlin : Springer. 
12. D. J. MEAD 1986 Journal of Sound and Vibration 104, 9-27. A new method of analysing wave motion in periodic structures: Applications to periodic Timoshenko beams and stiffened plates.

13. D. J. MEAD 1990 Journal of Sound and Vibration 141, 465-484. The harmonic response of uniform beams on multiple linear supports: A flexural wave analysis. 


\section{APPENDIX A: POINT MOBILITY OF A "SEMI-INFINITE" BEAM WITH CONSTANT CURVATURE}

In this appendix the response of a curved "semi-infinite" beam when excited at its free end or at a point along the beam is developed by considering the propagating and evanescent waves which travel in both directions along the beam. This method has previously been used to analyse the harmonic response of straight beams on periodic [12] and non-periodic supports [13]. In section A1 the response due to circumferential excitation at the free end is developed. Theoretical and experimental data for this type of structure have already been published in reference [8]. However, for completeness the theoretical derivation is repeated here. In section A2 the response of the beam when subjected to a radial excitation force at the free end derived. In sections $\mathrm{A} 3$ and $\mathrm{A} 4$ the response of the beam when excited at a position some distance from the free end is considered.

\section{A1. RESPONSE DUE TO CIRCUMFERENTIAL EXCITATION AT THE FREE END}

Assume that a "semi-infinite" beam with constant curvature is excited at its end by a point harmonic force, $F_{s} e^{i \omega t}$, acting in the circumferential direction as shown in Figure Al. At a given position along the beam the total lateral displacement, $\mathrm{w}_{+}(\mathrm{s}, \mathrm{t})$ or longitudinal displacement, $\mathrm{u}_{+}(\mathrm{s}, \mathrm{t})$ will be given by the sum of the displacements of the three possible waves in the beam [1] For example, above the ring frequency the total lateral displacement will be the sum of the lateral displacements due to a predominantly flexural travelling wave, a predominantly flexural nearfield wave, and a predominantly extensional travelling wave. Thus, the total lateral displacement is given by

$$
w_{+}(s)=A_{1+} e^{-i k_{1} s}+A_{2+} e^{-i k_{2} s}+A_{3+} e^{-i k_{3} s}
$$

where $A_{1_{+}}, A_{2+}$ and $A_{3_{+}}$represent the unknown wave amplitudes in the lateral direction and $\mathrm{k}_{1}, \mathrm{k}_{2}$ and $\mathrm{k}_{3}$ the respective wave numbers. For clarity of notation the harmonic term $\mathrm{e}^{\mathrm{i} \omega \mathrm{t}}$ has been omitted. The corresponding longitudinal displacement is given by 


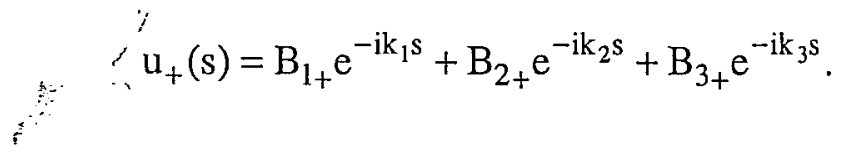

To determine the response of the structure the boundary conditions and applied loads at the free end of the beam, $s=0$, need to be evaluated. Flïgge based expressions for the resultant forces were derived in reference [1]. For circumferential excitation the axial force must be equal to externally applied force. Thus,

$$
N_{+}(0)=E S\left(\frac{w_{+}(0)}{R}+\frac{\partial u_{+}(0)}{\partial s}\right)+\frac{E I}{R}\left(\frac{w_{+}(0)}{R^{2}}+\frac{\partial^{2} w_{+}(0)}{\partial s^{2}}\right)=F_{s}
$$

Substituting the lateral and longitudinal displacements, equations (A1) and (A2), into the axial force, equation (A3), gives

$$
\begin{aligned}
& \mathrm{ES}\left[\left(\frac{1}{\mathrm{R}}-\mathrm{k}_{1} \delta_{1} \mathrm{i}\right) \mathrm{A}_{1+}+\left(\frac{1}{\mathrm{R}}-\mathrm{k}_{2} \delta_{2} \mathrm{i}\right) \mathrm{A}_{2+}+\left(\frac{1}{\mathrm{R}}-\mathrm{k}_{3} \delta_{3} \mathrm{i}\right) \mathrm{A}_{3+}\right] \\
& +\frac{\mathrm{EI}}{\mathrm{R}}\left[\left(\frac{1}{\mathrm{R}^{2}}-\mathrm{k}_{1}^{2}\right) \mathrm{A}_{1+}+\left(\frac{1}{\mathrm{R}^{2}}-\mathrm{k}_{2}^{2}\right) \mathrm{A}_{2+}+\left(\frac{1}{\mathrm{R}^{2}}-\mathrm{k}_{3}^{2}\right) \mathrm{A}_{3+}\right]=\mathrm{F}_{s},
\end{aligned}
$$

where $\delta_{j}=\frac{B_{j}}{A_{j}}$ is the longitudinal to lateral wave amplitude ratio, which for a given wave, can be determined from the equations of motion of the system [1]. Similarly, for purely circumferential excitation the bending moment must be zero. Thus,

$$
M_{+}(0)=-E I\left(\frac{w_{+}(0)}{R^{2}}+\frac{\partial^{2} w_{+}(0)}{\partial s^{2}}\right)=0
$$

Substituting the lateral and longitudinal displacements, equations (A1) and (A2), into the bending moment, equation (A5), gives 


$$
\left(\frac{1}{\mathrm{R}^{2}}-\mathrm{k}^{2}\right) \mathrm{A}_{1+}+\left(\frac{1}{\mathrm{R}^{2}}-\mathrm{k}_{2}^{2}\right) \mathrm{A}_{2+}+\left(\frac{1}{\mathrm{R}^{2}}-\mathrm{k}_{3}^{2}\right) \mathrm{A}_{3+}=0 .
$$

Likewise, the shear force must be zero. Thus,

$$
Q_{+}(0)=-E I \frac{\partial}{\partial s}\left(\frac{w_{+}(0)}{R^{2}}+\frac{\partial^{2} w_{+}(0)}{\partial s^{2}}\right)=0
$$

Substituting the lateral and longitudinal displacements, equations (A1) and (A2), into the shear force, equation (A7), gives

$$
\left(\frac{\mathrm{k}_{1}}{\mathrm{R}^{2}}-\mathrm{k}_{1}^{3}\right) \mathrm{A}_{1+}+\left(\frac{\mathrm{k}_{2}}{\mathrm{R}^{2}}-\mathrm{k}_{2}^{3}\right) \mathrm{A}_{2+}+\left(\frac{\mathrm{k}_{3}}{\mathrm{R}^{2}}-\mathrm{k}_{3}^{3}\right) \mathrm{A}_{3+}=0
$$

Equations (A4), (A6) and (A8) represent a set of three simultaneous equations in the unknown wave amplitudes $A_{1+}, A_{2+}$ and $A_{3+}$. For a given excitation frequency, $\omega$, the Flügge based equations of motion given in reference [1] can be solved to find the three possible wavenumbers, $\mathrm{k}_{\mathrm{j}}$, and the respective longitudinal to lateral displacement ratios, $\delta_{\mathrm{j}}$. Substituting these values into equations (A4), (A6) and (A8) and assuming unit force, $F_{S}=1$, enables the wave amplitude ratios $\left(A_{1+}: A_{2+}: A_{3+}\right)$ to be evaluated.

The cross receptance, $\alpha_{\mathrm{zF}_{\mathrm{s}}}(\omega)$ can now be calculated by evaluating the lateral displacement, equation (A1), at the excitation location. Thus,

$$
\alpha_{z F_{s}}(\omega)=\frac{W_{+}(0)}{F_{s}}=\frac{A_{1+}+A_{2+}+A_{3+}}{F_{s}}
$$


Using the longitudinal to lateral wave amplitude ratios, $\delta_{j}$, the point receptance, $\alpha_{\mathrm{sF}_{\mathrm{s}}}(\omega)$, can be calculated by evaluating the longitudinal displacement at the excitation location. Thus,

$$
\alpha_{s F_{s}}(\omega)=\frac{u_{+}(0)}{F_{s}}=\frac{B_{1+}+B_{2+}+B_{3+}}{F_{s}} .
$$

From the driving point receptance of the beam, equation (A10), the power supplied by a point force can be readily evaluated. This power is due to the product of the force and resultant velocity in the direction of the applied force and is a purely real quantity [10]. Thus,

$$
P_{\text {in }}=\left[\operatorname{Re}\left\{F_{s} e^{i \omega t}\right\}\right]\left[\operatorname{Re}\left\{u_{+} e^{i \omega t}\right\}\right] .
$$

In terms of the point mobility of the structure the power input per unit circumferential force can be expressed as

$$
\frac{\mathrm{P}_{\text {in }}}{\mathrm{G}_{\mathrm{F}_{\mathrm{s}} \mathrm{F}_{\mathrm{s}}}}=\operatorname{Re}\left\{\mathrm{Y}_{\mathrm{SF}_{\mathrm{s}}}\right\}
$$

\section{A2. RESPONSE DUE TO RADIAL EXCITATION AT THE FREE END}

The response due to radial excitation at the free end can be calculated in a similar manner to that of circumferential excitation described in section A1. Assume a "semi-infinite" beam with constant curvature is excited by a point harmonic force, $\mathrm{F}_{\mathrm{z}} \mathrm{e}^{\mathrm{i} \omega \mathrm{t}}$, acting in the radial direction as shown in Figure A2. The total lateral and longitudinal displacement is given by equations (A1) and (A2), respectively. However, the boundary conditions and applied loads at the free end, $\mathrm{s}=$ 0 , now reflect the radial excitation of the beam. Thus, the axial force is zero:

$$
N_{+}(0)=0 \text {. }
$$


Similarly, the bending moment is zero:

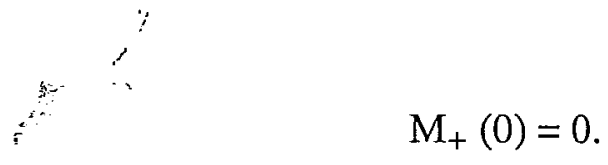

Likewise, the shear force is equal to the externally applied force. Thus,

$$
\mathrm{Q}_{+}(0)=\mathrm{F}_{\mathrm{Z}}
$$

Substituting the lateral and longitudinal displacements, equations (A1) and (A2), into the above boundary conditions and applied loadings leads to a set of simultaneous equations which can be solved numerically to find the point receptance (lateral displacement per unit radial excitation force). Thus,

$$
\alpha_{2 F_{z}}(\omega)=\frac{W_{+}(0)}{F_{z}}=\frac{A_{1+}+A_{2+}+A_{3+}}{F_{z}}
$$

The cross receptance (longitudinal displacement per unit radial excitation force) is given by

$$
\alpha_{\mathrm{sF}_{\mathrm{z}}}(\omega)=\frac{\mathrm{u}_{+}(0)}{\mathrm{F}_{\mathrm{z}}}=\frac{\mathrm{B}_{1+}+\mathrm{B}_{2+}+\mathrm{B}_{3+}}{\mathrm{F}_{\mathrm{z}}}
$$

The input power is the product of the radial force and the resultant lateral velocity. Thus,

$$
\mathrm{P}_{\text {in }}=\left[\operatorname{Re}\left\{\mathrm{F}_{\mathrm{z}} \mathrm{e}^{\mathrm{i} \omega \mathrm{t}}\right\}\right]\left[\operatorname { R e } \left\{\begin{array}{l}
\mathrm{o} \\
\left.\left.\mathrm{w}+\mathrm{e}^{\mathrm{i} \omega \mathrm{t}}\right\}\right] .
\end{array}\right.\right.
$$

In terms of the point mobility the power input per unit radial force is

$$
\frac{P_{\text {in }}}{G_{F_{z} F_{z}}}=\operatorname{Re}\left\{Y_{z_{z}}\right\}
$$




\section{A3. RESPONSE DUE TO ÇIRCUMFERENTIAL EXCITATION AT A POINT ALONG THE BEAM}

Assume a "semi-infinite" beam with constant curvature is excited by a point harmonic force, $F_{S} e^{i \omega t}$, acting in the circumferential direction at a position, $s_{0}$, some distance from the free end of the beam, as shown in Figure A3. The response at any position, $\mathrm{s}_{\mathrm{r}}$, along the beam will be due to : (i) the forced waves generated by the external force; and (ii) the free waves reflected from the boundary at the free end. Thus, the total lateral displacement to the right of the force is given by

$$
\begin{gathered}
\mathrm{w}_{+}\left(\mathrm{s}_{\mathrm{r}}\right)=\mathrm{L}_{1+} \mathrm{e}^{-\mathrm{k}_{1} \mathrm{~s}_{\mathrm{r}} \mathrm{i}}+\mathrm{L}_{2+} \mathrm{e}^{-\mathrm{k}_{2} \mathrm{~s}_{\mathrm{r}} \mathrm{i}}+\mathrm{L}_{3+} \mathrm{e}^{-\mathrm{k}_{3} \mathrm{~s}_{\mathrm{r}} \mathrm{i}} \\
+\mathrm{A}_{1+} \mathrm{e}^{-\mathrm{k}_{1}\left(\mathrm{~s}_{\mathrm{r}}-\mathrm{s}_{\mathrm{o}}\right) \mathrm{i}}+\mathrm{A}_{2+} \mathrm{e}^{-\mathrm{k}_{2}\left(\mathrm{~s}_{\mathrm{r}}-\mathrm{s}_{0}\right) \mathrm{i}}+\mathrm{A}_{3+} \mathrm{e}^{-\mathrm{k}_{3}\left(\mathrm{~s}_{\mathrm{r}}-\mathrm{s}_{0}\right) \mathrm{i}},
\end{gathered}
$$

where $\mathrm{L}_{1+}, \mathrm{L}_{2+}$ and $\mathrm{L}_{3+}$ are the unknown lateral displacements of the waves reflected from the free end and $\mathrm{A}_{1+}, \mathrm{A}_{2+}$ and $\mathrm{A}_{3+}$ are the lateral displacements of corresponding waves in an infinite curved beam excited by a point harmonic force acting in the circumferential direction. The corresponding longitudinal displacement to the right of the force is given by

$$
\begin{aligned}
& u_{+}\left(s_{r}\right)=\delta_{1} L_{1+} e^{-k_{1} s_{r} i}+\delta_{2} L_{2+} e^{-k_{2} s_{r} i}+\delta_{3} L_{3+} e^{-k_{3} s_{r} i} \\
& \left(s_{r} s_{o}\right)+B_{1+} e^{-k_{1}\left(s_{r}-s_{0}\right) i}+B_{2+} e^{-k_{2}\left(s_{r}-s_{0}\right) i}+B_{3+} e^{-k_{3}\left(s_{r}-s_{o}\right) i}
\end{aligned}
$$

where $\mathrm{B}_{1+}, \mathrm{B}_{2+}$ and $\mathrm{B}_{3+}$ are the longitudinal displacements of the corresponding waves of the infinite curved beam system. The lateral displacement to the left of the force is constructed by taking account of the left going nature of the waves due to the applied force. Thus, 


$$
\begin{aligned}
& \mathrm{w}_{-}\left(\mathrm{s}_{\mathrm{r}}\right)=\mathrm{L}_{1+} \mathrm{e}^{-\mathrm{k}_{1} \mathrm{~s}_{\mathrm{r}} \mathrm{i}}+\mathrm{L}_{2+} \mathrm{e}^{-\mathrm{k}_{2} \mathrm{~s}_{\mathrm{r}} \mathrm{i}}+\mathrm{L}_{3+} \mathrm{e}^{-\mathrm{k}_{3} \mathrm{~s}_{\mathrm{r}} \mathrm{i}} \\
& \left(\mathrm{s}_{\mathrm{r}} \mathrm{s}_{\mathrm{o}}\right)+\mathrm{A}_{1-} \mathrm{e}^{\mathrm{k}_{1}\left(\mathrm{~s}_{\mathrm{o}}-\mathrm{s}_{\mathrm{r}}\right) \mathrm{i}}+\mathrm{A}_{2-} \mathrm{e}^{\mathrm{k}_{2}\left(\mathrm{~s}_{\mathrm{o}}-\mathrm{s}_{\mathrm{r}}\right) \mathrm{i}}+\mathrm{A}_{3-} \mathrm{e}^{\mathrm{k}_{3}\left(\mathrm{~s}_{\mathrm{o}}-\mathrm{s}_{\mathrm{r}}\right) \mathrm{i}} .
\end{aligned}
$$

The corresponding longitudinal displacement to the left of the force is given by

$$
\begin{aligned}
& \mathrm{u}_{-}\left(\mathrm{s}_{\mathrm{r}}\right)=\delta_{1} \mathrm{~L}_{1+} \mathrm{e}^{-\mathrm{k}_{1} \mathrm{~s}_{\mathrm{r}} \mathrm{i}}+\delta_{2} \mathrm{~L}_{2+} \mathrm{e}^{-\mathrm{k}_{2} \mathrm{~s}_{\mathrm{r}} \mathrm{i}}+\delta_{3} \mathrm{~L}_{3+} \mathrm{e}^{-\mathrm{k}_{3} \mathrm{~s}_{\mathrm{r}} \mathrm{i}} \\
& \left(\mathrm{s}_{\mathrm{r}} \mathrm{s}_{\mathrm{o}}\right)+\mathrm{B}_{1-} \mathrm{e}^{\mathrm{k}_{1}\left(\mathrm{~s}_{\mathrm{o}}-\mathrm{s}_{\mathrm{r}}\right) \mathrm{i}}+\mathrm{B}_{2-} \mathrm{e}^{\mathrm{k}_{2}\left(\mathrm{~s}_{\mathrm{o}}-\mathrm{s}_{\mathrm{r}}\right) \mathrm{i}}+\mathrm{B}_{3-} \mathrm{e}^{\mathrm{k}_{3}\left(\mathrm{~s}_{\mathrm{o}}-\mathrm{s}_{\mathrm{r}}\right) \mathrm{i}}
\end{aligned}
$$

where $\mathrm{B}_{1_{-}}, \mathrm{B}_{2_{-}}$and $\mathrm{B}_{3_{-}}$are the longitudinal displacements of the corresponding waves of the infinite curved beam system.

The value of the unknown free wave coefficients, $L_{j+}$, can be found by satisfying the boundary conditions at the free end of the beam. For a free end it is assumed that all resultant forces are zero. Thus, the extensional force is zero:

$$
N_{+}(0)=E S\left(\frac{w_{-}(0)}{R}+\frac{\partial u_{-}(0)}{\partial s}\right)+\frac{E I}{R}\left(\frac{w_{-}(0)}{R^{2}}+\frac{\partial w_{-}(0)}{\partial s^{2}}\right)=0
$$

Substituting the lateral and longitudinal displacements, equations (A22) and (A23), into equation (A24) gives

$$
\begin{aligned}
& {\left[E S\left(\frac{1}{R}-k_{1} \delta_{1} i\right)+\frac{E I}{R}\left(\frac{1}{R^{2}}-k_{1}^{2}\right)\right] L_{1+}} \\
& +\left[E S\left(\frac{1}{R}-k_{2} \delta_{2} i\right)+\frac{E I}{R}\left(\frac{1}{R^{2}}-k_{2}^{2}\right)\right] L_{2+} \\
& +\left[E S\left(\frac{1}{R}-k_{3} \delta_{3} i\right)+\frac{E I}{R}\left(\frac{1}{R^{2}}-k_{3}^{2}\right)\right] L_{3+}
\end{aligned}
$$




$$
\begin{aligned}
= & -\left\{\left[E S\left(\frac{1}{R}+k_{1} \delta_{1-} i\right)+\frac{E I}{R}\left(\frac{1}{R^{2}}-k_{1}^{2}\right)\right] A_{1-}\right. \\
& +\left[E S\left(\frac{1}{R}+k_{2} \delta_{2-} i\right)+\frac{E I}{R}\left(\frac{1}{R^{2}}-k_{2}^{2}\right)\right] A_{2-} \\
& \left.+\left[E S\left(\frac{1}{R}+k_{3} \delta_{3-} i\right)+\frac{E I}{R}\left(\frac{1}{R^{2}}-k_{3}^{2}\right)\right] A_{3-}\right\}
\end{aligned}
$$

where $\delta_{j-}$ is the longitudinal to lateral wave amplitude ratio for left going waves i.e. $\delta_{j_{-}-}=\frac{B_{j_{-}}}{A_{j-}}$. Because of the symmetry of left and right going waves the modulus of $\delta_{\mathrm{j}}$ and $\delta_{\mathrm{j}}$ - will be equal, however, they may have opposite phase. Similarly, the bending moment is zero. Thus,

$$
M_{+}(0)=-E I\left(\frac{w_{-}(0)}{R^{2}}+\frac{\partial^{2} w_{-}(0)}{\partial s^{2}}\right)=0
$$

Substituting the lateral and longitudinal displacements, equations (A22) and (A23), into equation (A26) gives

$$
\begin{aligned}
& \left(\frac{1}{\mathrm{R}^{2}}-\mathrm{k}_{1}^{2}\right) \mathrm{L}_{1+}+\left(\frac{1}{\mathrm{R}^{2}}-\mathrm{k}_{2}^{2}\right) \mathrm{L}_{2+}+\left(\frac{1}{\mathrm{R}^{2}}-\mathrm{k}_{3}^{2}\right) \mathrm{L}_{3+} \\
= & -\left\{\left(\frac{1}{\mathrm{R}^{2}}-\mathrm{k}_{1}^{2}\right) \mathrm{A}_{1-}+\left(\frac{1}{\mathrm{R}^{2}}-\mathrm{k}_{2}^{2}\right) \mathrm{A}_{2-}+\left(\frac{1}{\mathrm{R}^{2}}-\mathrm{k}_{3}^{2}\right) \mathrm{A}_{3-}\right\} .
\end{aligned}
$$

Likewise, the third boundary condition is that the shear force is zero. Thus, 


$$
Q_{+}(0)=-\mathrm{EI} \frac{\partial}{\partial s}\left(\frac{w_{-}(0)}{R^{2}}+\frac{\partial^{2} w_{-}(0)}{\partial s^{2}}\right)=0
$$

Substituting the lateral and longitudinal displacements, equations (A22) and (A23), into equation (A28) gives

$$
\begin{aligned}
& -\mathrm{k}_{1} \mathrm{i}\left(\frac{1}{\mathrm{R}^{2}}-\mathrm{k}_{1}^{2}\right) \mathrm{L}_{1+}-\mathrm{k}_{2} \mathrm{i}\left(\frac{1}{\mathrm{R}^{2}}-\mathrm{k}_{2}^{2}\right) \mathrm{L}_{2+}-\mathrm{k}_{3} \mathrm{i}\left(\frac{1}{\mathrm{R}^{2}}-\mathrm{k}_{3}^{2}\right) \mathrm{L}_{3+} \\
= & -\left\{i \mathrm{k}_{1}\left(\frac{1}{\mathrm{R}^{2}}-\mathrm{k}_{1}^{2}\right) \mathrm{A}_{1-}+\mathrm{i} \mathrm{k}_{2}\left(\frac{1}{\mathrm{R}^{2}}-\mathrm{k}_{2}^{2}\right) \mathrm{A}_{2-}+\mathrm{i} \mathrm{k}_{3}\left(\frac{1}{\mathrm{R}^{2}}-\mathrm{k}_{3}^{2}\right) \mathrm{A}_{3-}\right\} .
\end{aligned}
$$

Equations (A25), (A27) and (A29) represent a set of three simultaneous equations in the unknown wave amplitudes $\mathrm{L}_{1+}, \mathrm{L}_{2+}$ and $\mathrm{L}_{3+}$. For a given excitation frequency, $\omega$, these equations can be solved to find the free wave amplitude ratio, $\left(\mathrm{L}_{\mathrm{H}_{+}}: \mathrm{L}_{2+}: \mathrm{L}_{3+}\right)$. The point receptance can now be calculated by evaluating the longitudinal displacement, equation (A23), at the excitation location, $s=s_{0}$. Thus,

$$
\begin{gathered}
\alpha_{s} P_{s}(\omega)=\frac{u_{-}\left(s_{0}\right)}{F_{s}}=\left\{\delta_{1} L_{1+} e^{-k_{1} s_{0} i}+\delta_{2} L_{2+} e^{-k_{2} s_{o} i}\right. \\
\left.+\delta_{3} L_{3+} e^{-k_{3} s_{0} i}+B_{1-}+B_{2-}+B_{3-}\right\} / F_{s} .
\end{gathered}
$$

Similarly the cross receptance can be calculated by evaluating the lateral displacement, equation (A22), at the excitation location, $\mathrm{s}=\mathrm{s}_{\mathrm{O}}$. Thus,

$$
\alpha_{z_{s}}(\omega)=\frac{W_{-}(0)}{F_{s}}=\left\{L_{1+} e^{-k_{1} s_{0} i}+L_{2+} e^{-k_{2} s_{0} i}+L_{3+} e^{-k_{3} s_{0} i}\right.
$$




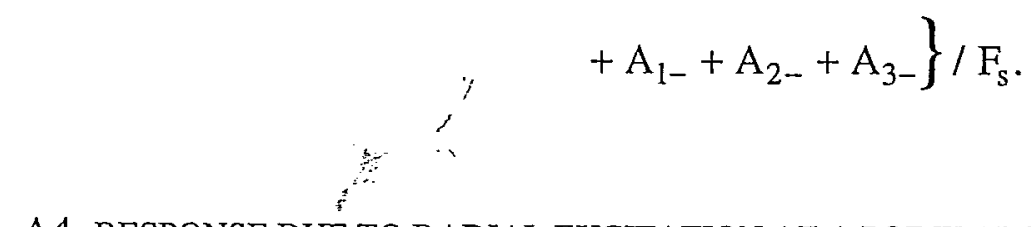

\section{A4. RESPONSE DUE TO RADIAL EXCITATION AT A POINT ALONG THE BEAM}

Assume now a "semi-infinite" beam with constant curvature is excited by a point harmonic force, $F_{z} e^{i \omega t}$, acting in the radial direction at a position, $s_{o}$, some distance from the free end of beam as shown in Figure 4. By ah́alogy with the previous section the response at any position, $\mathrm{s}_{\mathrm{r}}$, along the beam will be due to : (i) the forced waves generated by the external force, and; (ii) the free waves reflected from the boundary at the free end. The lateral displacement to the left of the force is constructed by taking account of the left going nature of the waves due to the applied force. Thus,

$$
\begin{aligned}
w_{-}\left(s_{r}\right)= & L_{1+} e^{-k_{1} s_{r} i}+L_{2+} e^{-k_{2} s_{r} i}+L_{3+} e^{-k_{3} s_{r} i} \\
\left(s_{r} s_{0}\right)= & +A_{1-} e^{k_{1}\left(s_{o}-s_{r}\right) i}+A_{2-} e^{k_{2}\left(s_{o}-s_{r}\right) i}+A_{3-} e^{k_{3}\left(s_{o}-s_{r}\right) i} .
\end{aligned}
$$

The corresponding longitudinal displacement to the left of the force is given by

$$
\begin{aligned}
& \mathrm{u}_{-}\left(\mathrm{s}_{\mathrm{r}}\right)=\delta_{1} \mathrm{~L}_{1+} \mathrm{e}^{-\mathrm{k}_{1} \mathrm{~s}_{\mathrm{r}} \mathrm{i}}+\delta_{2} \mathrm{~L}_{2+} \mathrm{e}^{-\mathrm{k}_{2} \mathrm{~s}_{\mathrm{r}} \mathrm{i}}+\delta_{3} \mathrm{~L}_{3+} \mathrm{e}^{-\mathrm{k}_{3} \mathrm{~s}_{\mathrm{r}} \mathrm{i}} \\
& \left(\mathrm{s}_{\mathrm{r}} \mathrm{s}_{\mathrm{o}}\right)+\mathrm{B}_{1-} \mathrm{e}^{\mathrm{k}_{1}\left(\mathrm{~s}_{\mathrm{o}}-\mathrm{s}_{\mathrm{r}}\right) \mathrm{i}}+\mathrm{B}_{2-} \mathrm{e}^{\mathrm{k}_{2}\left(\mathrm{~s}_{\mathrm{o}}-\mathrm{s}_{\mathrm{r}}\right) \mathrm{i}}+\mathrm{B}_{3-} \mathrm{e}^{\mathrm{k}_{3}\left(\mathrm{~s}_{\mathrm{o}}-\mathrm{s}_{\mathrm{r}}\right) \mathrm{i}} .
\end{aligned}
$$

Although these expressions are identical in appearance to equation (A22) and (A23) the forced wave amplitudes $A_{j-}$ and $B_{j-}$ in equations (A32) and (A33) are those of the infinite curved beam system excited by a point force acting in the radial direction.

The value of the unknown coefficients $L_{1+}, L_{2+}$ and $L_{3+}$ in equations (A32) and (A33) are found by satisfying the boundary conditions at the free end. At the free end it is assumed that the resultant forces are zero. Thus, substituting the displacements, equations (A32) and (A33), into the resultant forces, equations (A24), (A26) and (A28), gives a set of three simultaneous equations which can be solved to find the free wave amplitude ratio $\left(L_{1_{+}}: L_{2+}: L_{3+}\right)$. The point 
receptance, $\alpha_{\mathrm{z}_{\mathrm{z}}}(\omega)$, is calculated by evaluating the lateral displacement, equation (A32), at the excitation location, $\mathrm{s}_{\mathrm{o}}$. Thus,

$$
\begin{gathered}
\alpha_{z_{z}}(\omega)=\frac{W_{-}\left(s_{0}\right)}{F_{z}}=\left\{L_{1+} e^{-k_{1} s_{0} i}+L_{2+} e^{-k_{2} s_{0} i}+L_{3+} e^{-k_{3} s_{0} i}\right. \\
\left.+A_{1-}+A_{2-}+A_{3-}\right\} / F_{z}
\end{gathered}
$$

Similarly the cross receptance, $\alpha_{s_{z}}(\omega)$, is calculated by evaluating the longitudinal displacement, equation (A33), at the excitation location, $\mathrm{s}_{\mathrm{O}}$. Thus,

$$
\begin{gathered}
\alpha_{s} \mathrm{~F}_{z}(\omega)=\frac{\mathrm{u}_{-}\left(s_{0}\right)}{\mathrm{F}_{\mathrm{z}}}=\left\{\delta_{1} \mathrm{~L}_{1+} \mathrm{e}^{-\mathrm{k}_{1} \mathrm{~s}_{\mathrm{o}} \mathrm{i}}+\delta_{2} \mathrm{~L}_{2+} \mathrm{e}^{-\mathrm{k}_{2} \mathrm{~s}_{\mathrm{o}} \mathrm{i}}+\delta_{3} \mathrm{~L}_{3+} \mathrm{e}^{-\mathrm{k}_{3} \mathrm{~s}_{\mathrm{o}} \mathrm{i}}\right. \\
\left.+\mathrm{B}_{1-}+\mathrm{B}_{2-}+\mathrm{B}_{3-}\right\} / \mathrm{F}_{\mathrm{z}} .
\end{gathered}
$$




\section{APPENDIX B: NOTATION}

A lateral displacement of a given wave

B longitudinal displacement of a given wave

E Young's modulus

$\mathrm{F}_{\mathrm{S}} \quad$ magnitude of externally applied force acting in circumferential direction

$\mathrm{F}_{\mathrm{z}} \quad$ magnitude of externally applied force acting in radial direction

G(f) single sided spectral density function

I second moment of area of cross-section of beam

L lateral displacement of wave reflected from free end

M bending moment on cross-section of beam

$\mathrm{N} \quad$ circumferential force on cross-section of beam

$\mathrm{P}_{\mathrm{bm}} \quad$ bending moment component of transmitted power ${ }^{1}$

$\mathrm{P}_{\mathrm{e}} \quad$ extensional component of transmitted power

$\mathrm{P}_{\text {in }} \quad$ input power

$\mathrm{P}_{\mathrm{sf}} \quad$ shear force component of transmitted power

Q shear force on cross-section of beam

$\mathrm{R} \quad$ radius of curvature

S cross-sectional area of beam

$\mathrm{Y(f)} \quad$ mobility

$a_{u} \quad$ longitudinal acceleration

$\mathrm{a}_{\mathrm{W}} \quad$ lateral acceleration

$\mathrm{a}_{\mathrm{i}} \quad$ radially mounted accelerometer signal

$a_{\mathrm{ui}} \quad$ circumferentially mounted accelerometer signal

$c_{0} \quad$ wavespeed of purely extensional waves in a straight bar

f frequency in $\mathrm{Hz}$

$\mathrm{k} \quad$ wavenumber

S

co-ordinate in circumferential direction

$\mathrm{s}_{\mathrm{O}} \quad$ transmitted power measurement position 


$\begin{array}{ll}\mathrm{s}_{\mathrm{r}} & \text { response position along beam } \\ \mathrm{s}_{\mathrm{u}} & \text { circumferentially mounted accelerometer position } \\ \mathrm{t} & \text { displacement at centre-line in circumferential direction } \\ \mathrm{u} & \text { displacement at centre-line in radial direction } \\ \mathrm{W} & \text { co-ordinate in radial direction } \\ \mathrm{z} & \text { distance between radially mounted accelerometers } \\ \Delta_{\mathrm{f}} & \text { distance between circumferentially mounted accelerometers } \\ \Delta_{\mathrm{u}} & \text { non-dimensional frequency } \\ \Omega & \text { receptance }\end{array}$

$\delta \quad$ longitudinal to lateral displacement ratio of a given wave

$\omega$ radian frequency

Special symbols

$\operatorname{Im}\{\} \quad$ imaginary part

$\operatorname{Re}\{\} \quad$ real part

$<>_{\mathrm{t}} \quad$ time average

- time derivative

Subscripts

$+\quad$ positive direction

negative direction

1 The term "power flow", although not physically accurate, has gained widespread acceptance. In this paper the term "transmitted power" will be used to denote the power (in Watts) flowing through a beam. 
Table 1

Physical properties of the experimental beam

Density, $\rho\left(\mathrm{kg} / \mathrm{m}^{3}\right)$

Young's modulus, E (N/m $\left.\mathrm{m}^{3}\right) \quad 207 \times 10^{9}$

Radius of curvature, $\mathrm{R}(\mathrm{m}) \quad 1.0$

Breadth, b (m) $\quad 0.05$

Depth, d (m) $6.07 \times 10^{-3}$ 


\section{FIGURE CAPTIONS}

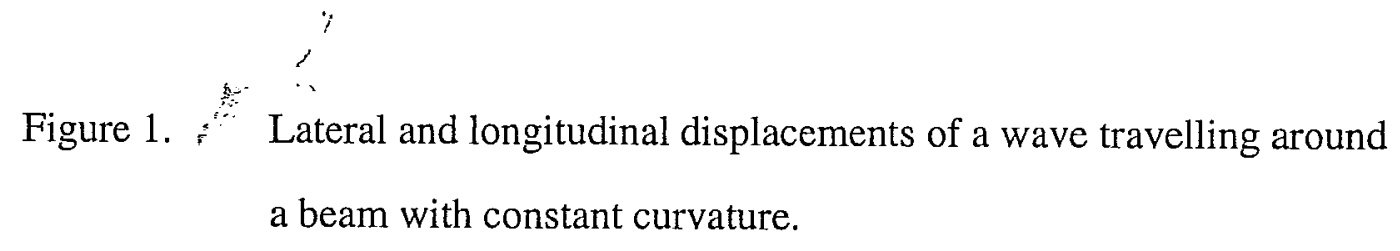

Figure 2. Schematic representation of the four measurement locations, $s_{1}, s_{2}$, $\mathrm{s}_{3}$, and $\mathrm{s}_{4}$, used to approximate the lateral acceleration, $\mathrm{a}_{\mathrm{w}}$, and its spatial derivatives at position $\mathrm{s}_{0}$.

Figure 3. Schematic representation of the two measurement locations, $\mathrm{s}_{\mathrm{u} 2}$ and $\mathrm{s}_{\mathrm{u} 3}$ used to approximate the longitudinal acceleration, $\mathrm{a}_{\mathrm{u}}$, and its first spatial derivative at position $\mathrm{s}_{0}$.

Figure 4. Schematic representation of the experimental apparatus: (a) side view; (b) top view.

Figure 5. Schematic representation of transducer configuration used to measure transmitted power.

Figure 6. Real part of the point mobility of the experimental beam when excited by a force acting in the circumferential direction at the free end (predicted data marked with "o" symbols).

Figure 7. Time-averaged vibrational power transmitted along the experimental beam when excited by a force acting in the circumferential direction at the free end: (a) input power; (b) total transmitted power; (c) "straight" extensional component; (d) "curved" extensional component; and (e) "straight" flexural component.

Figure 8. Real part of the point mobility of the experimental beam when excited by a force acting in the radial direction at the free end (predicted data marked with "o" symbols).

Figure 9. Time-averaged vibrational power transmitted along the experimental beam when excited by a force acting in the radial direction at the free end: (a) input power; (b) "straight" flexural 
component; (c) "straight" extensional component; and (d) "curved" extensional component.

Figure $10 . \quad$ Real part of the point mobility of the experimental beam when excited by a force acting in the circumferential direction at a point $0.6 \mathrm{~m}$ from the free end (predicted data marked with "o" symbols).

Figure 11. Time-averaged vibrational power transmitted along the experimental beam when excited by a force acting in the circumferential direction at a point $0.6 \mathrm{~m}$ from the free end: (a) input power; (b) total transmitted power; (c) "straight" extensional component; (d) "curved" extensional component; and (e) "straight" flexural component.

Figure 12. Real part of the point mobility of the experimental beam when excited by a force acting in the radial direction at a point $0.6 \mathrm{~m}$ from the free end (predicted data marked with "o" symbols).

Figure 13. Time-averaged vibrational power transmitted along the experimental beam when excited by a force acting in the radial direction at a point $0.6 \mathrm{~m}$ from the free end: (a) input power; (b) "straight" flexural component; (c) "straight" extensional component; and (d) "curved" extensional component.

Figure A1. Diagram of the response of a "semi-infinite" beam with constant curvature when excited by a force acting in the circumferential direction at the free end.

Figure A2. Diagram of the response of a "semi-infinite" beam with constant curvature when excited by a force acting in the radial direction at the free end.

Figure A3. Diagram of the response of a "semi-infinite" beam with constant curvature when excited by a force acting in the circumferential direction at a point, $\mathrm{s}_{0}$, along the beam. 
Figure A4. Diagram of the response of a "semi-infinite" beam with constant currvature when excited by a force acting in the radial direction at a point, $\mathrm{s}_{0}$, along the beam. 
$\stackrel{3}{\prime}$

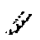

Lateral displacement, $w(s, t)$

Radial direction, z

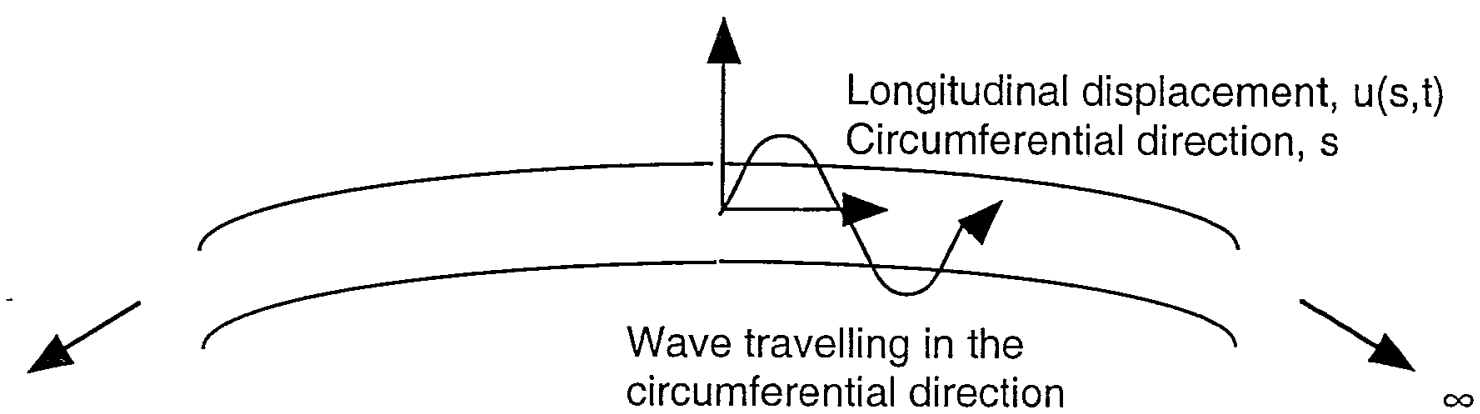


Fig 2

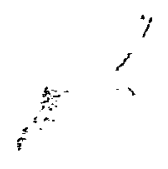

Lateral acceleration, $a_{w}$

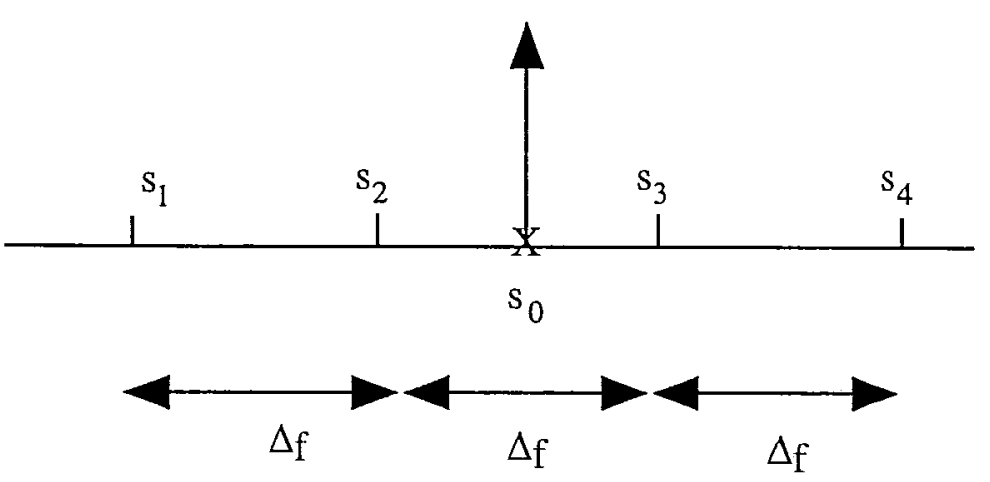


Fig 3

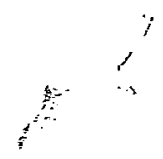

Longitudinal

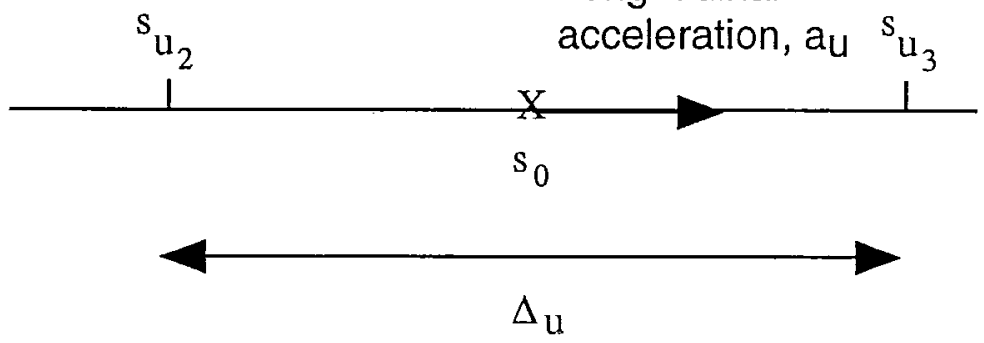



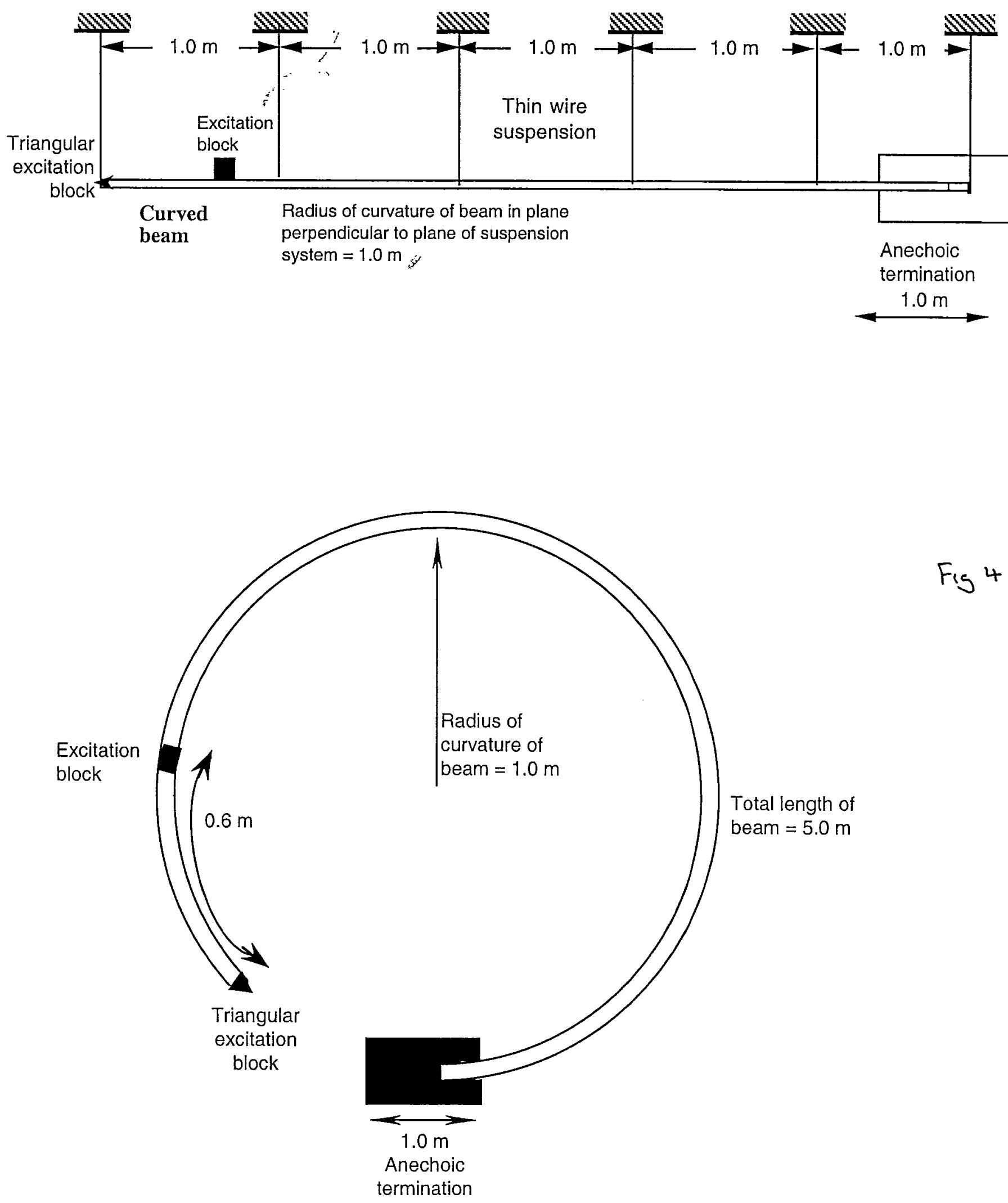

$F(g)(b)$ 
Fig 5

$3^{\prime}$

$\dot{y}$

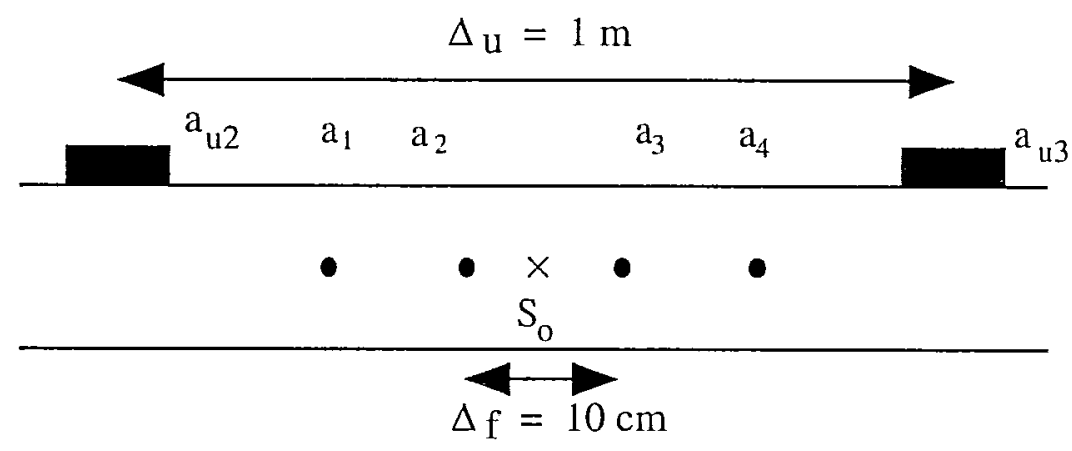


Fig 6

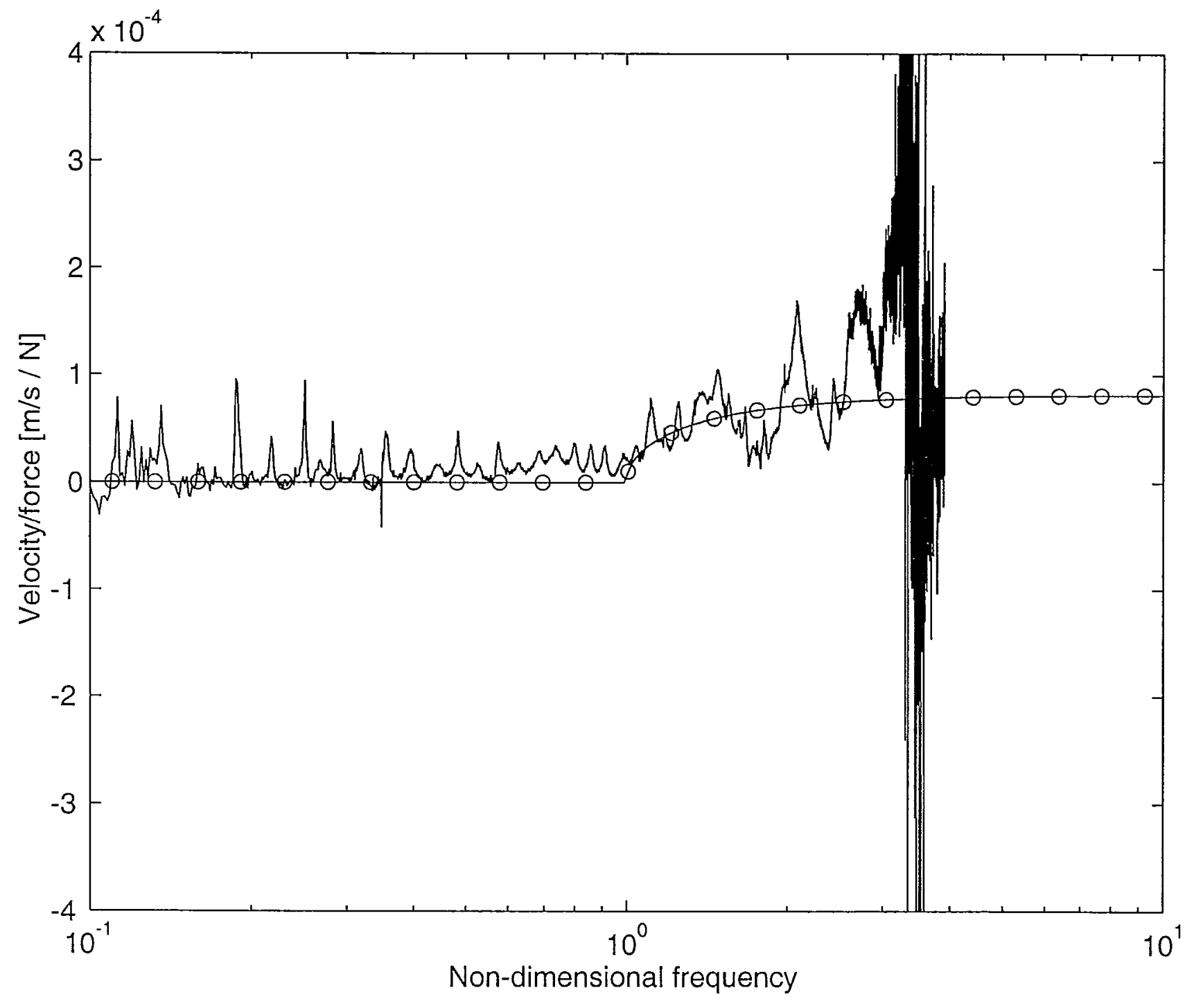


Fig $7(a)$

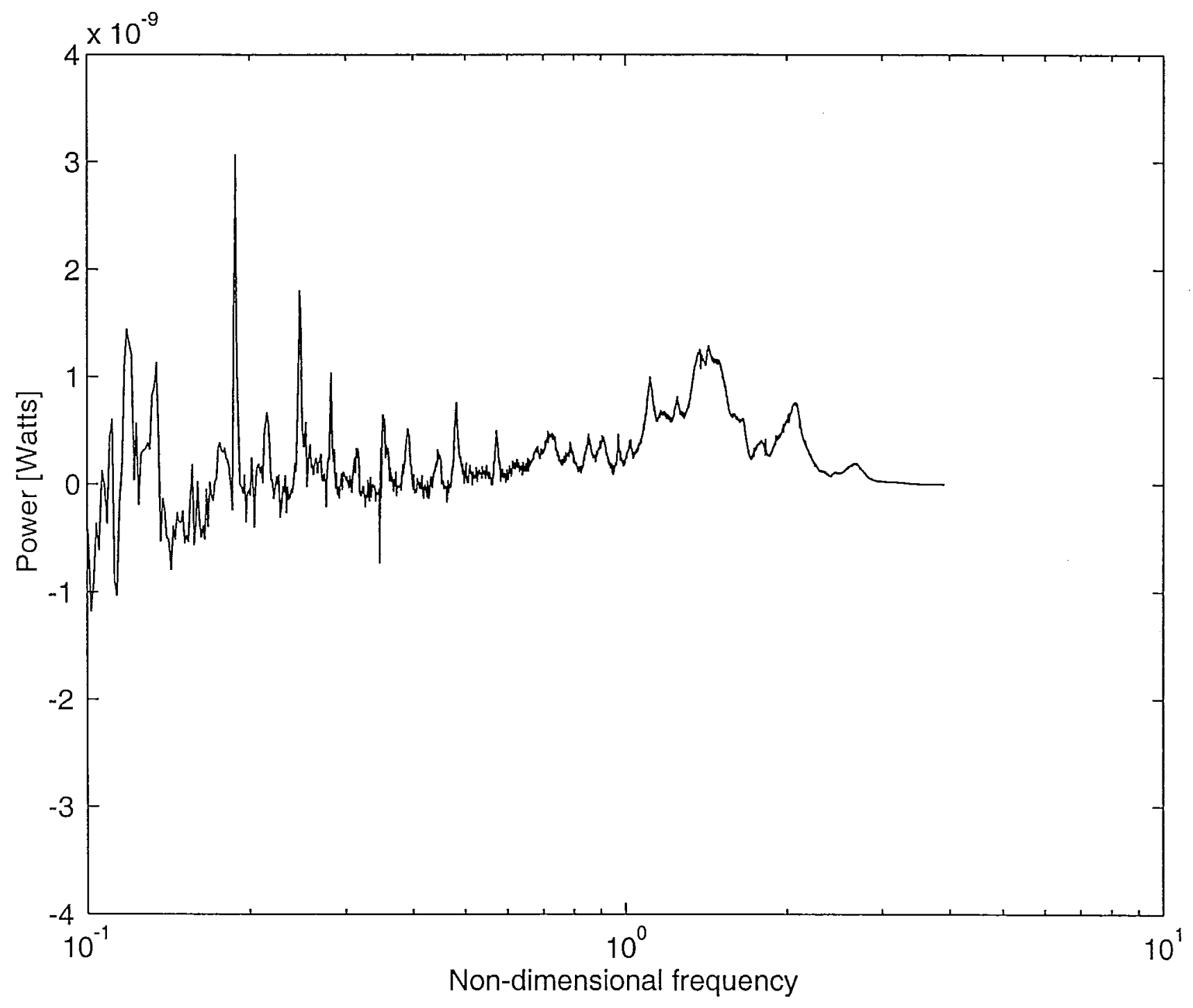


$F g 7(b)$

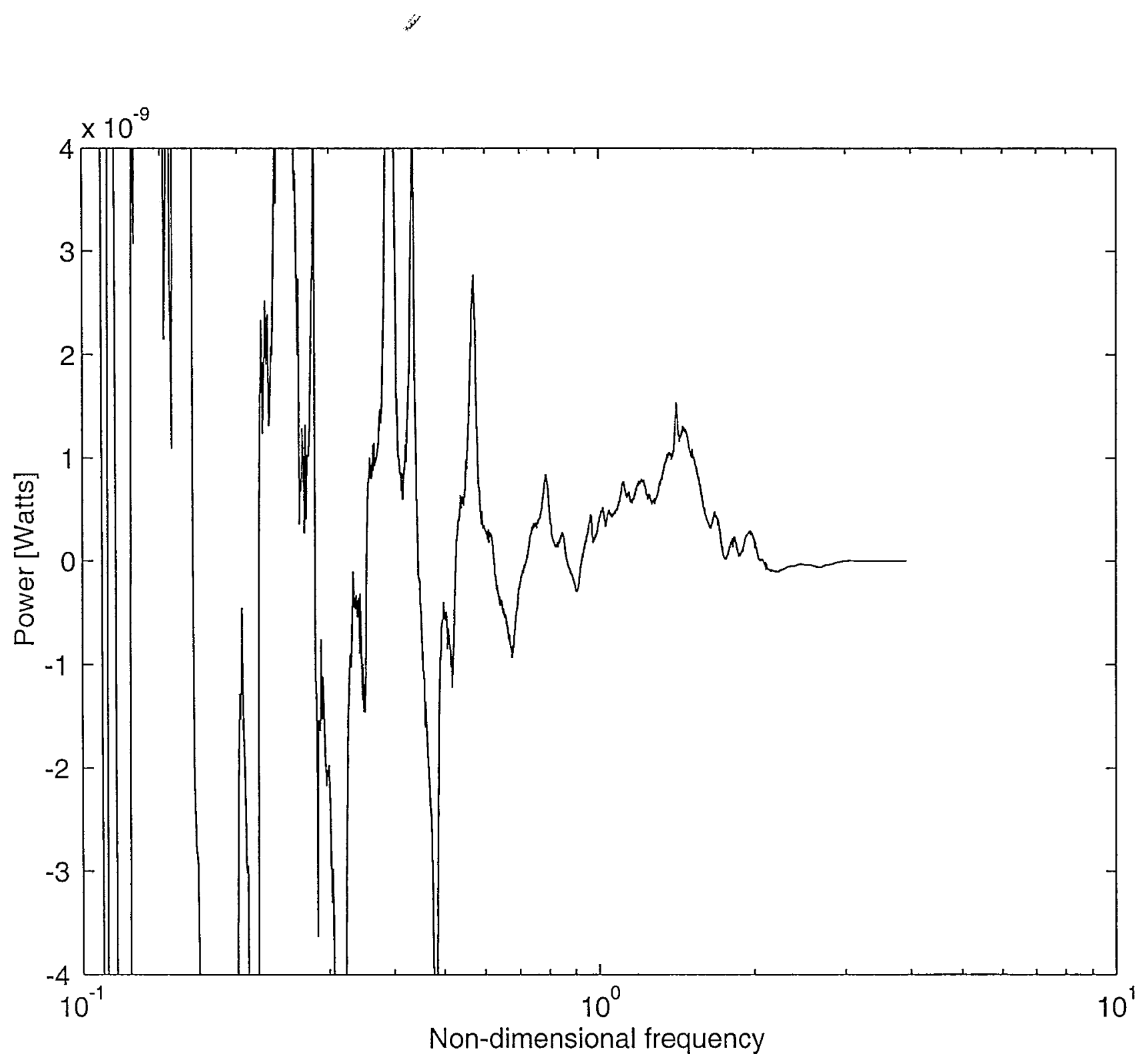




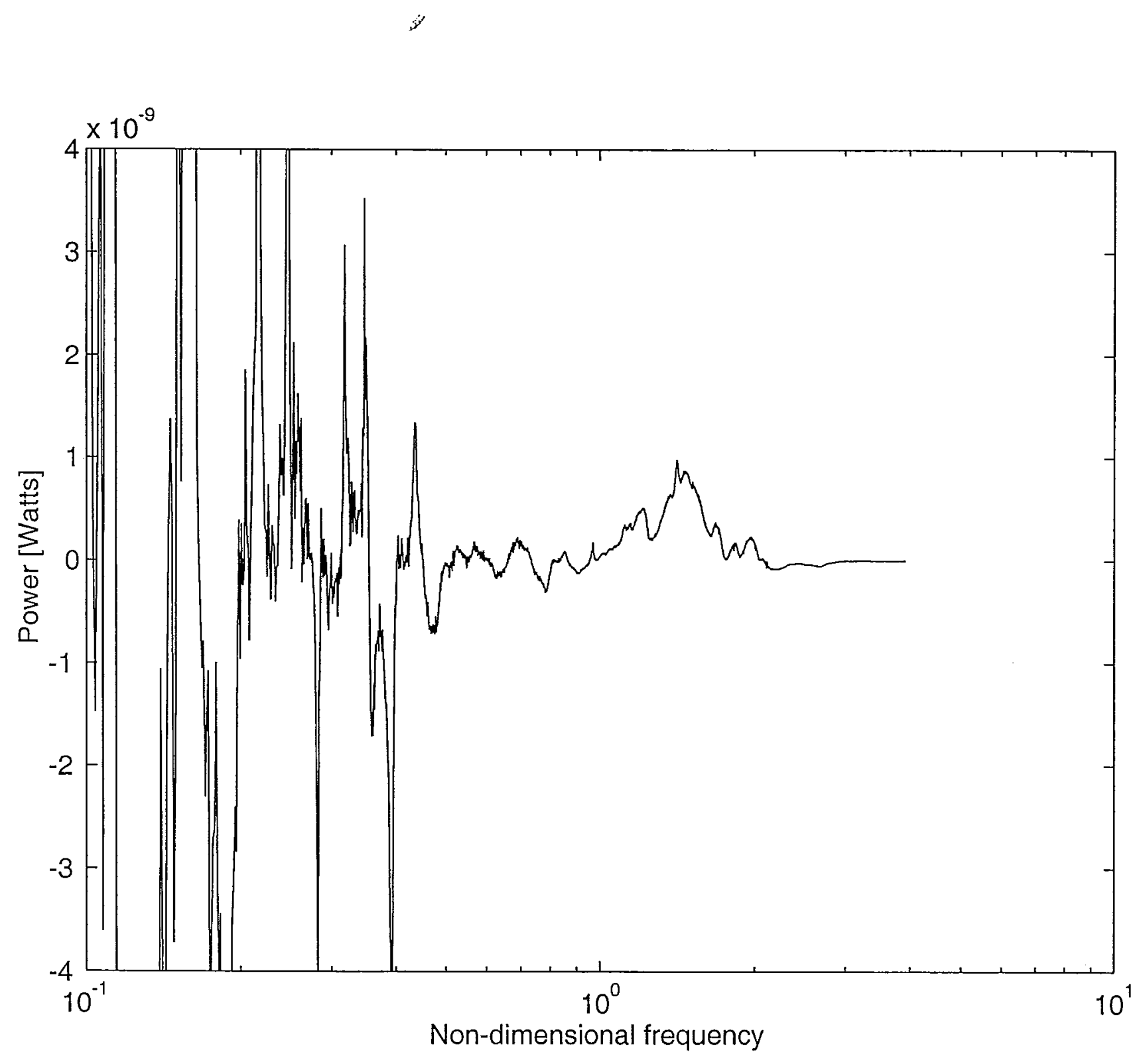


Fiy $7(d)$
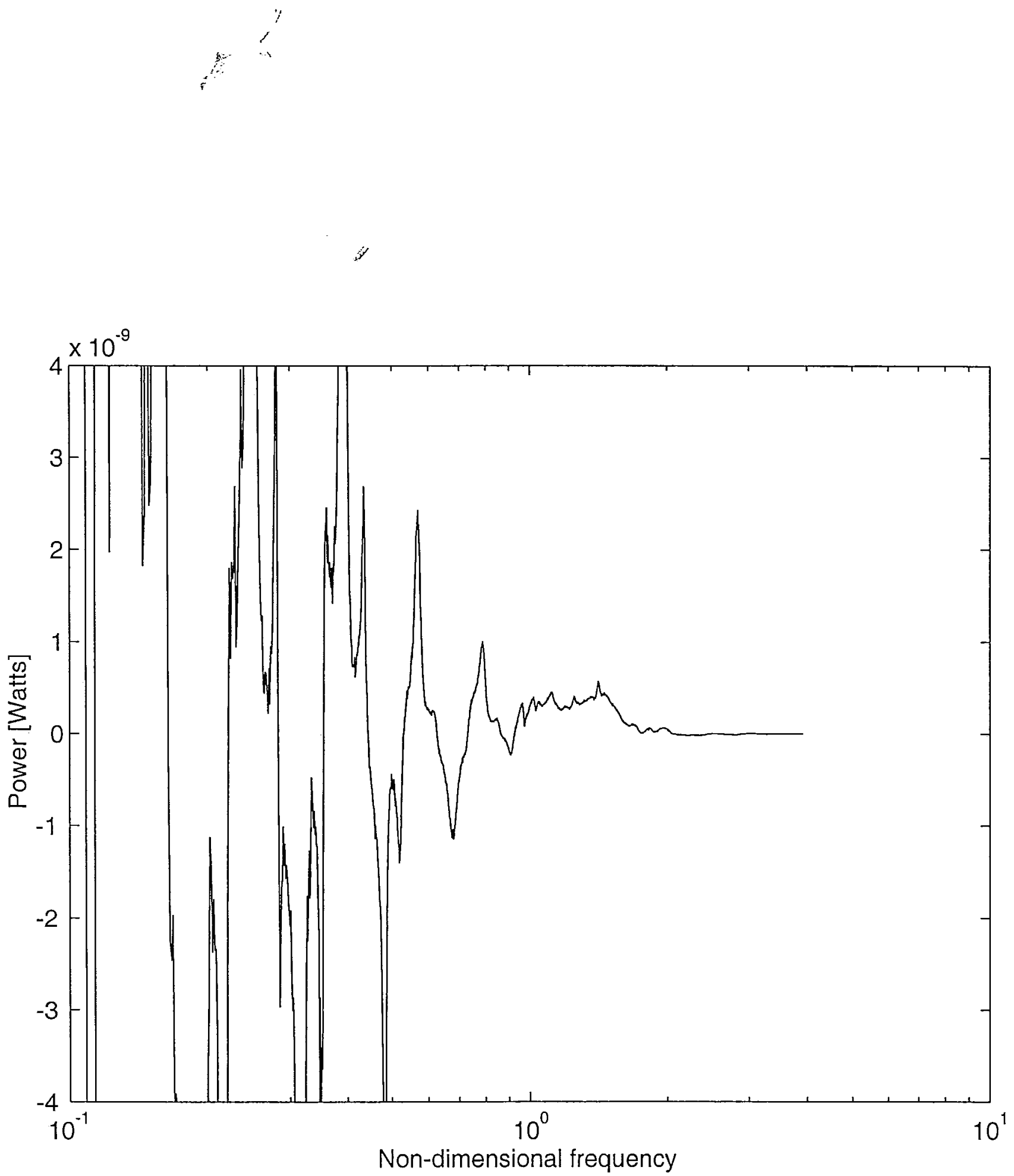


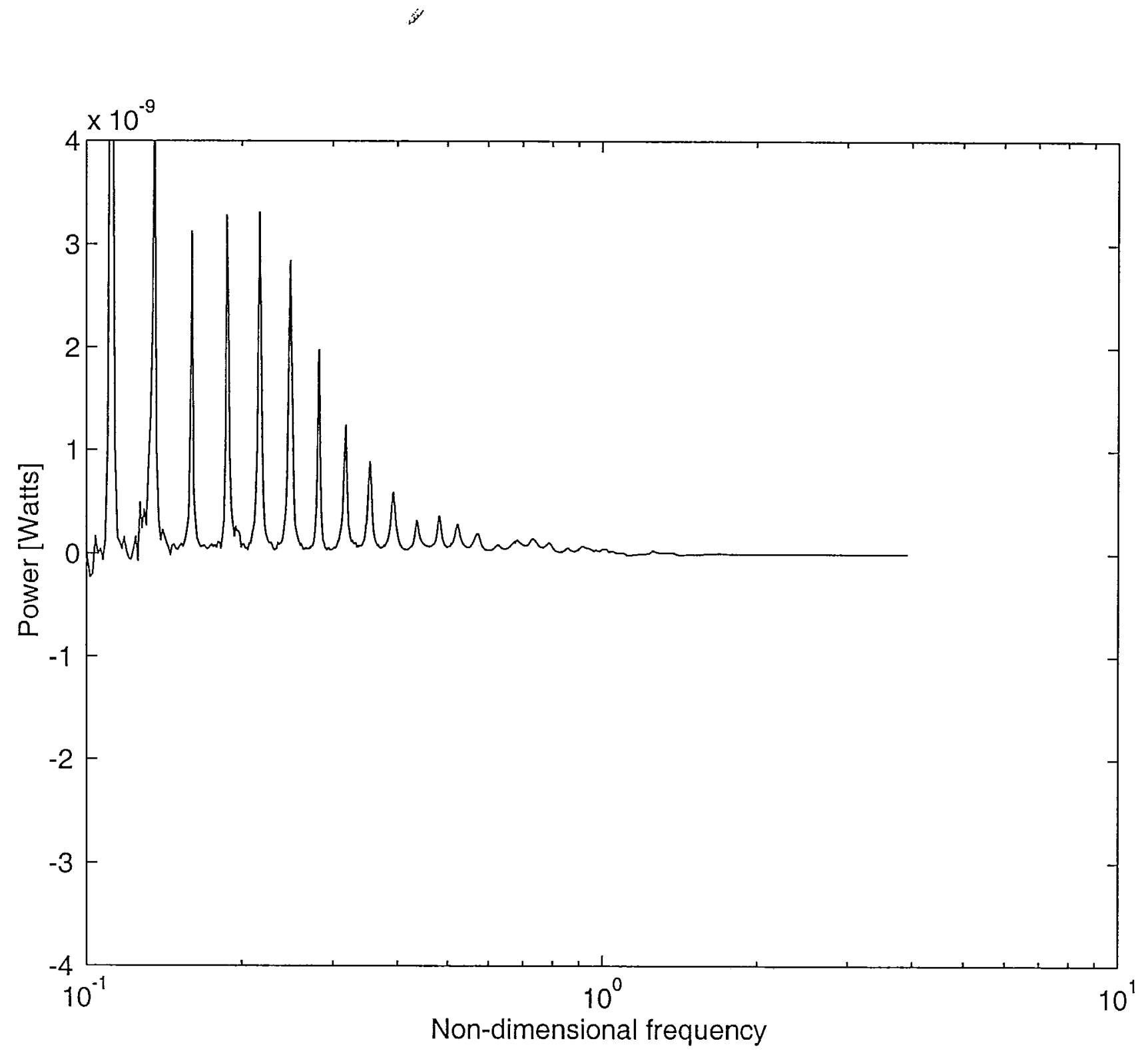


Fig 8

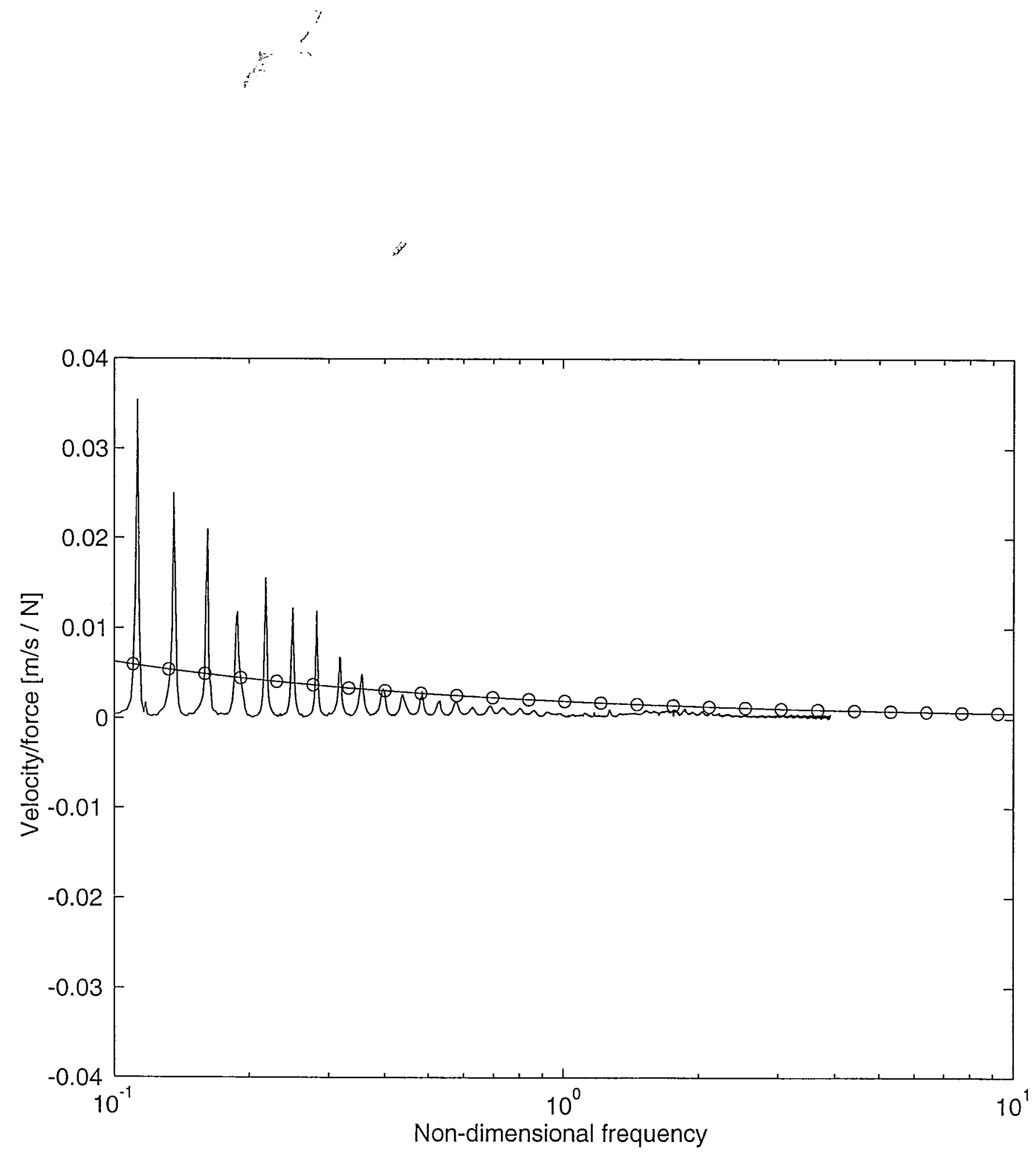




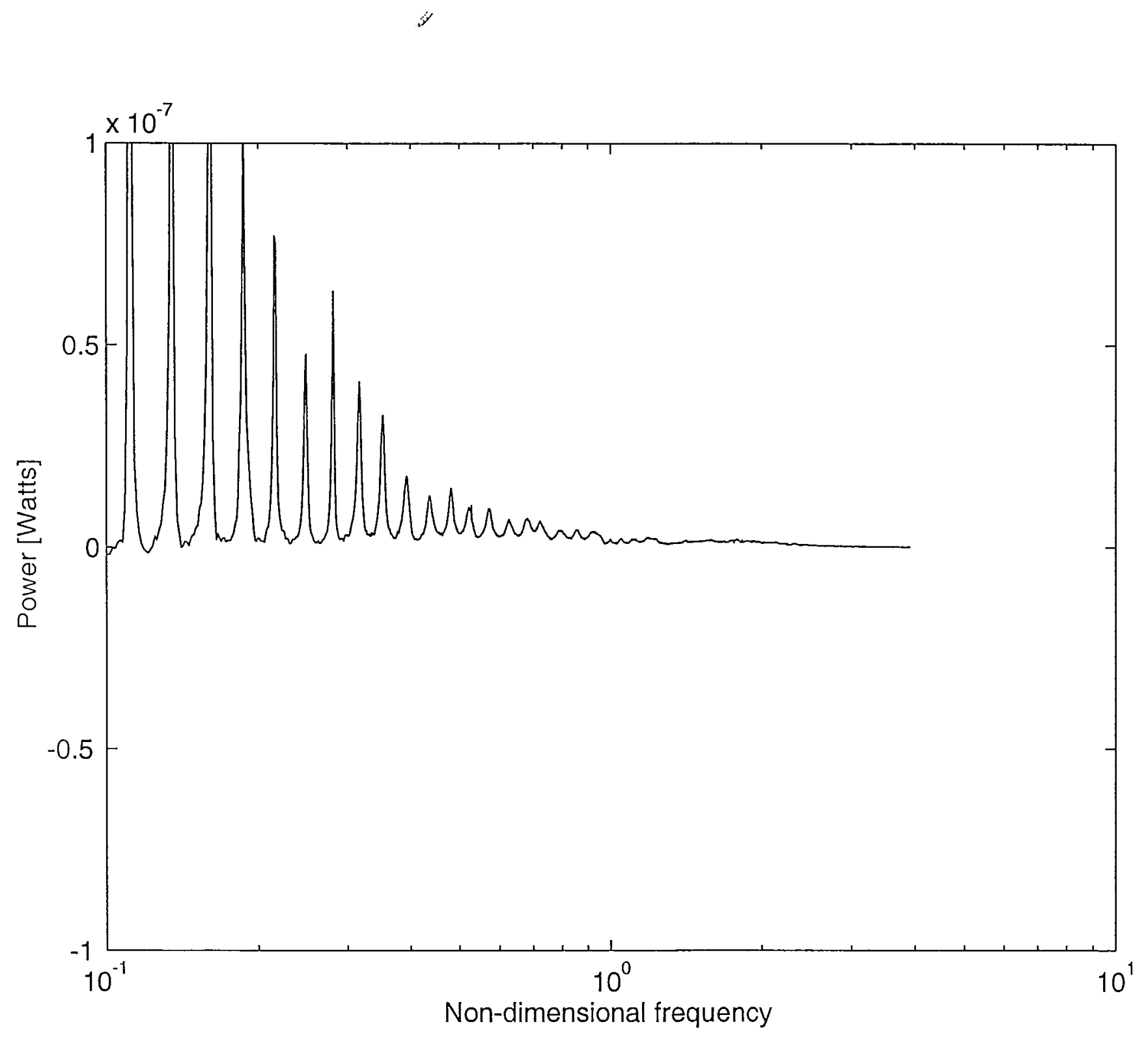




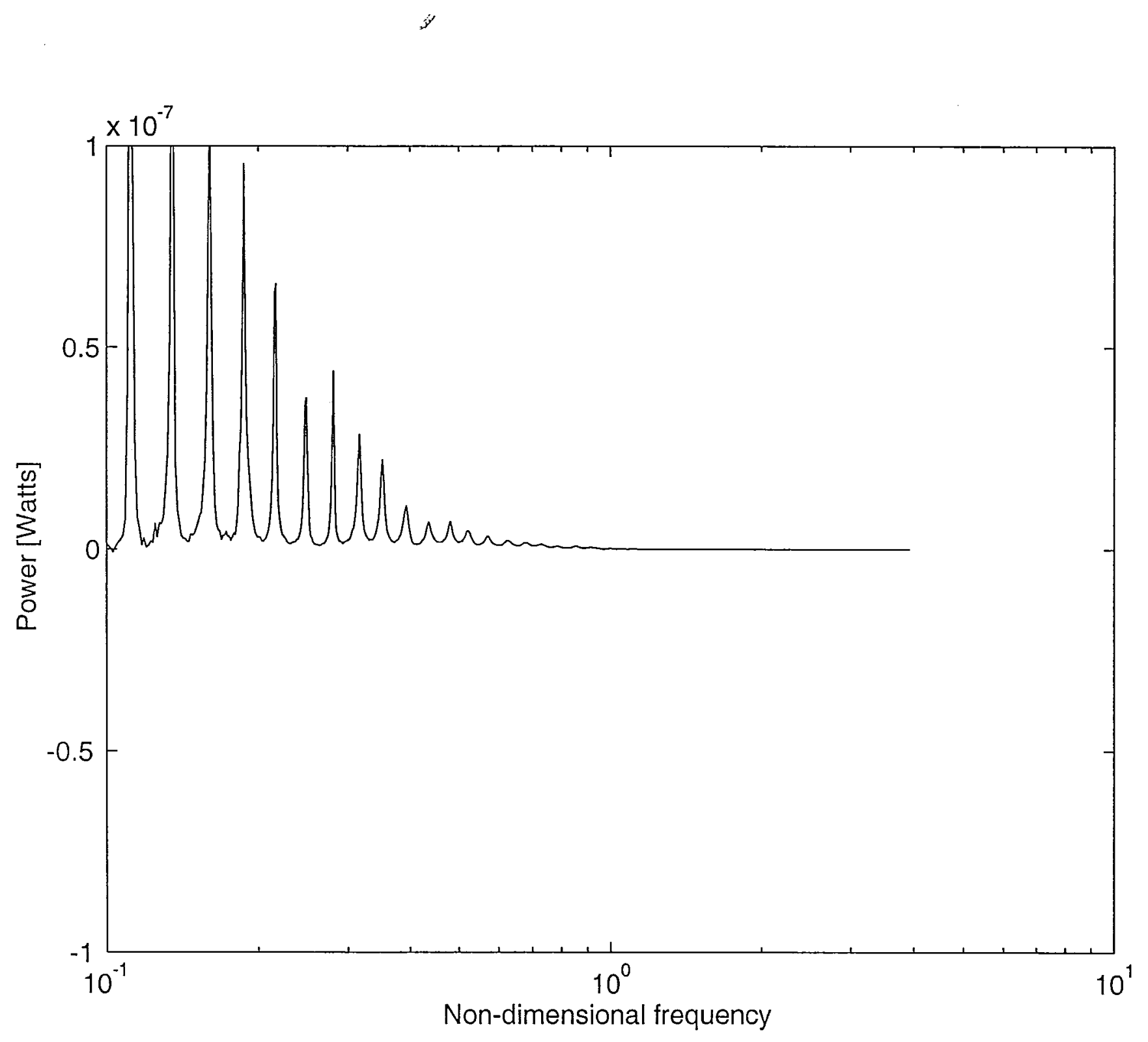


Fig $9(c)$

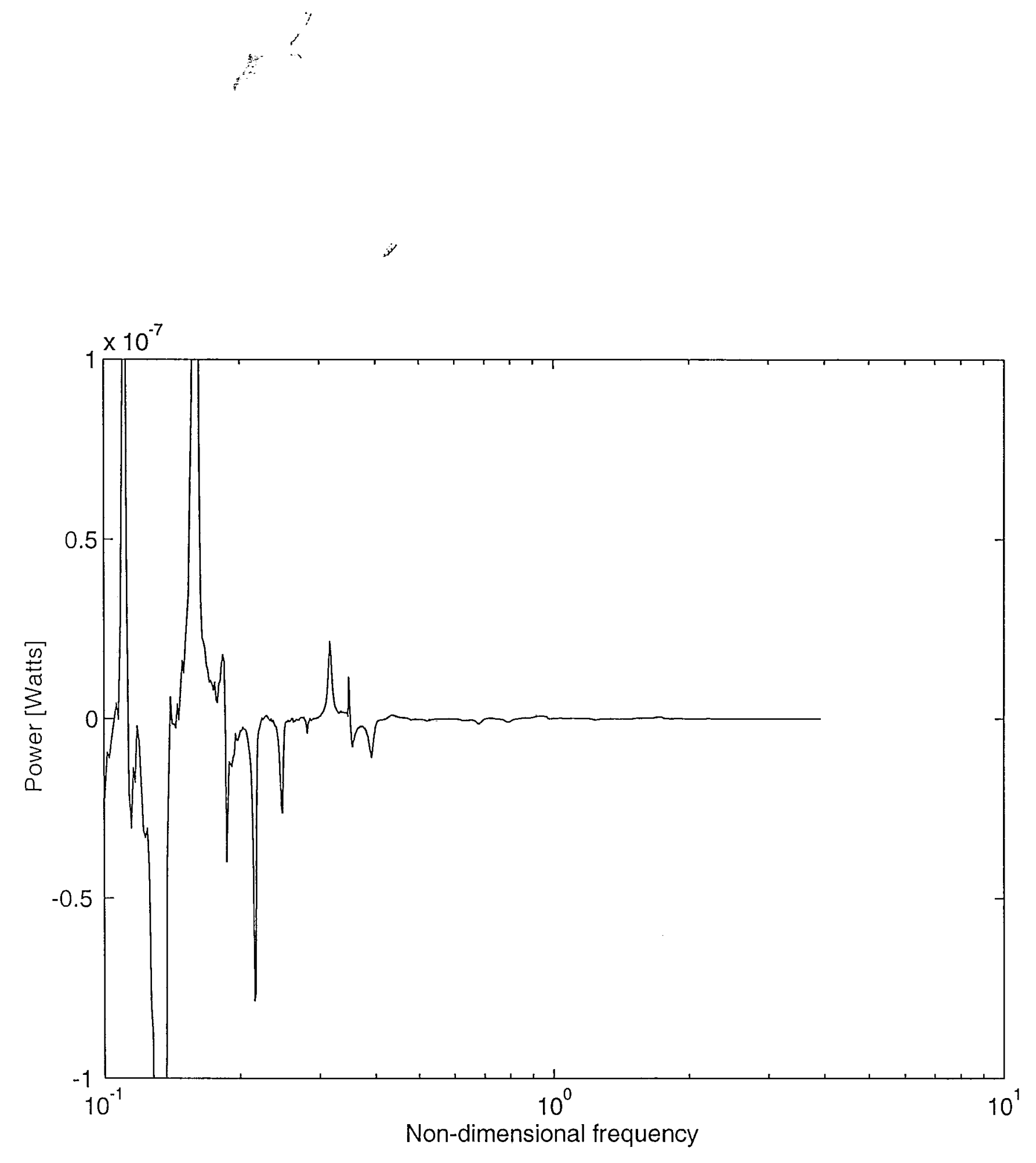


Fig $9(d)$

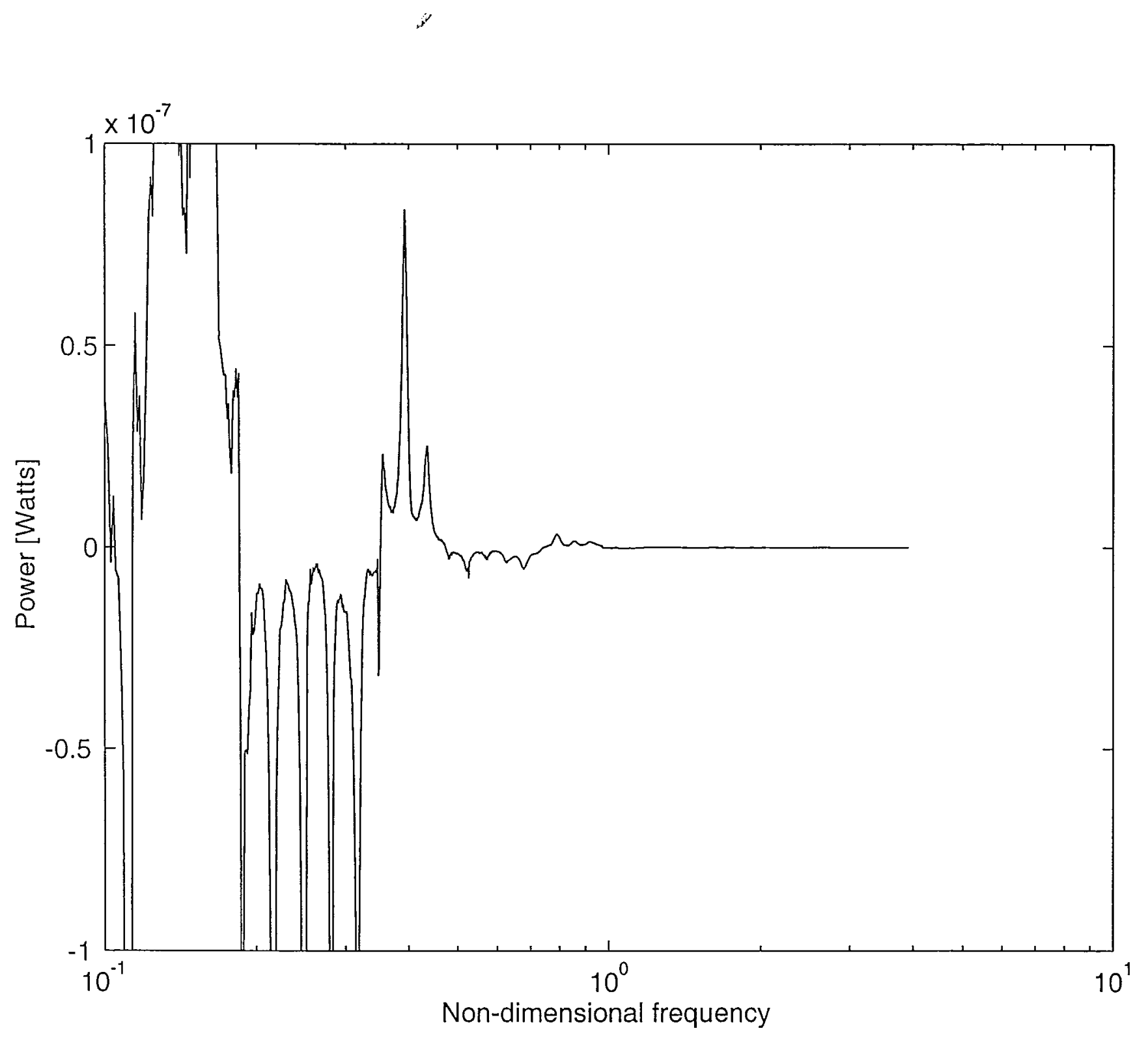


Fig 10

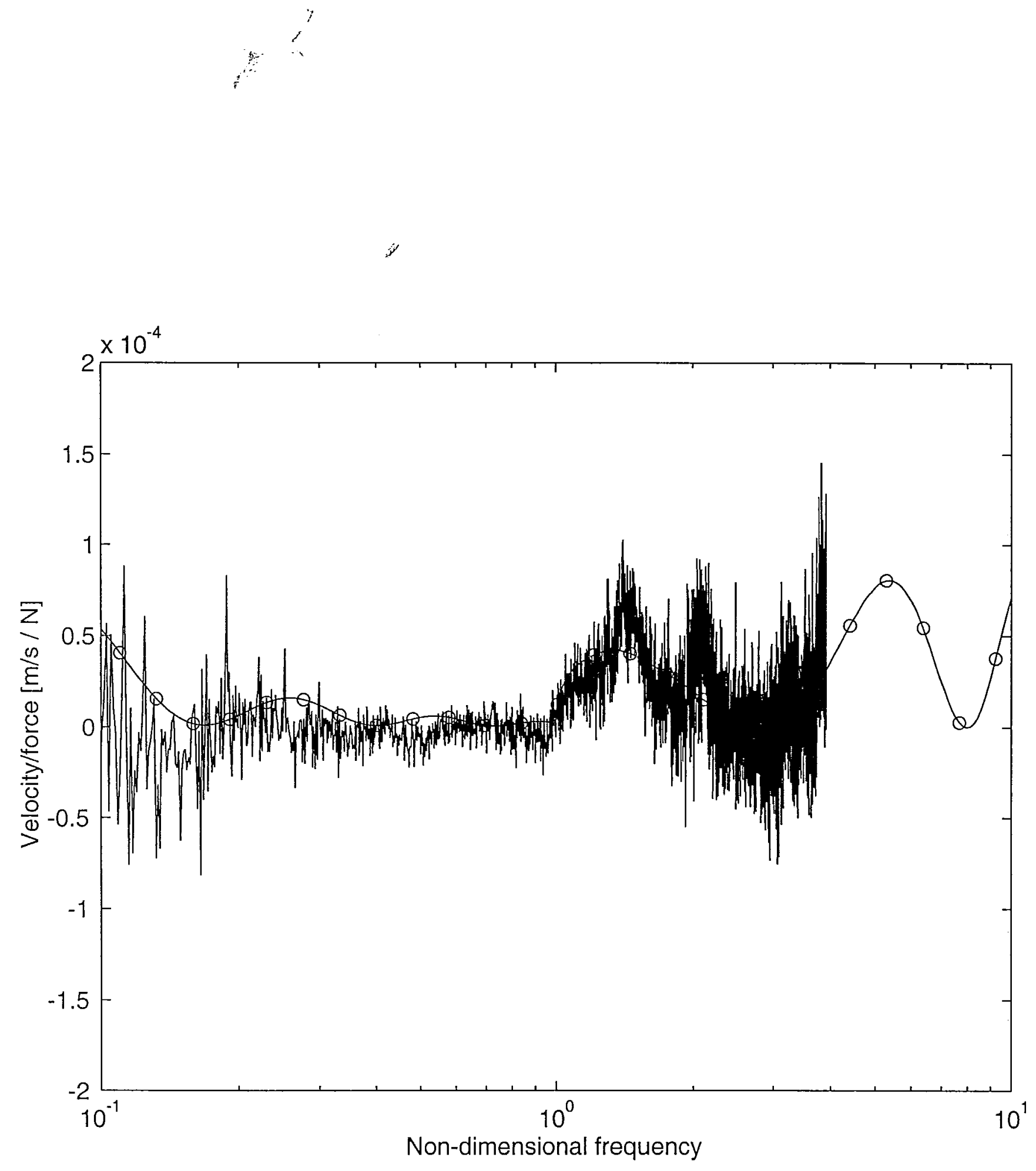


$F_{1 g} \|(a)$

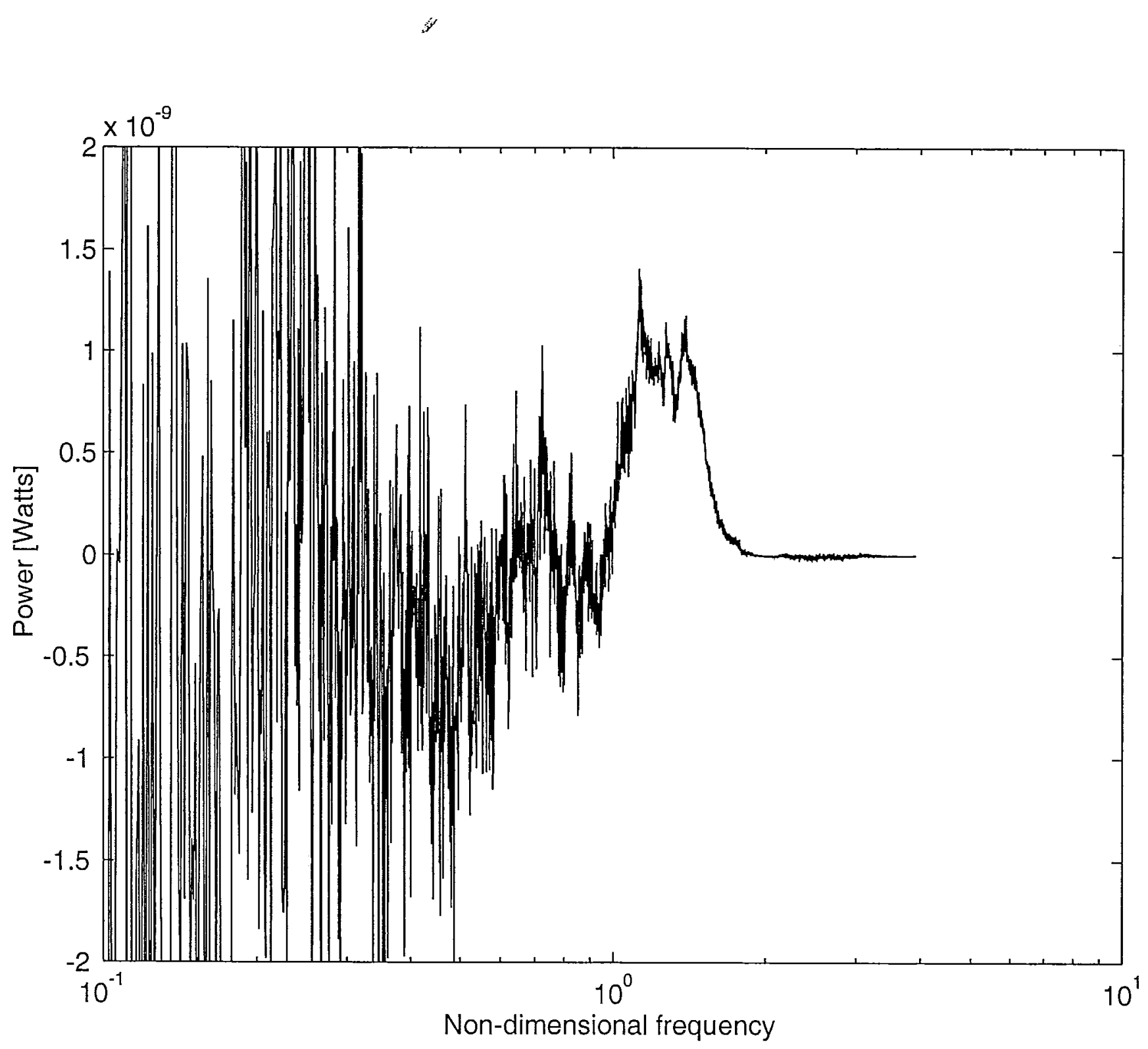


$F \cdot g \|(b)$

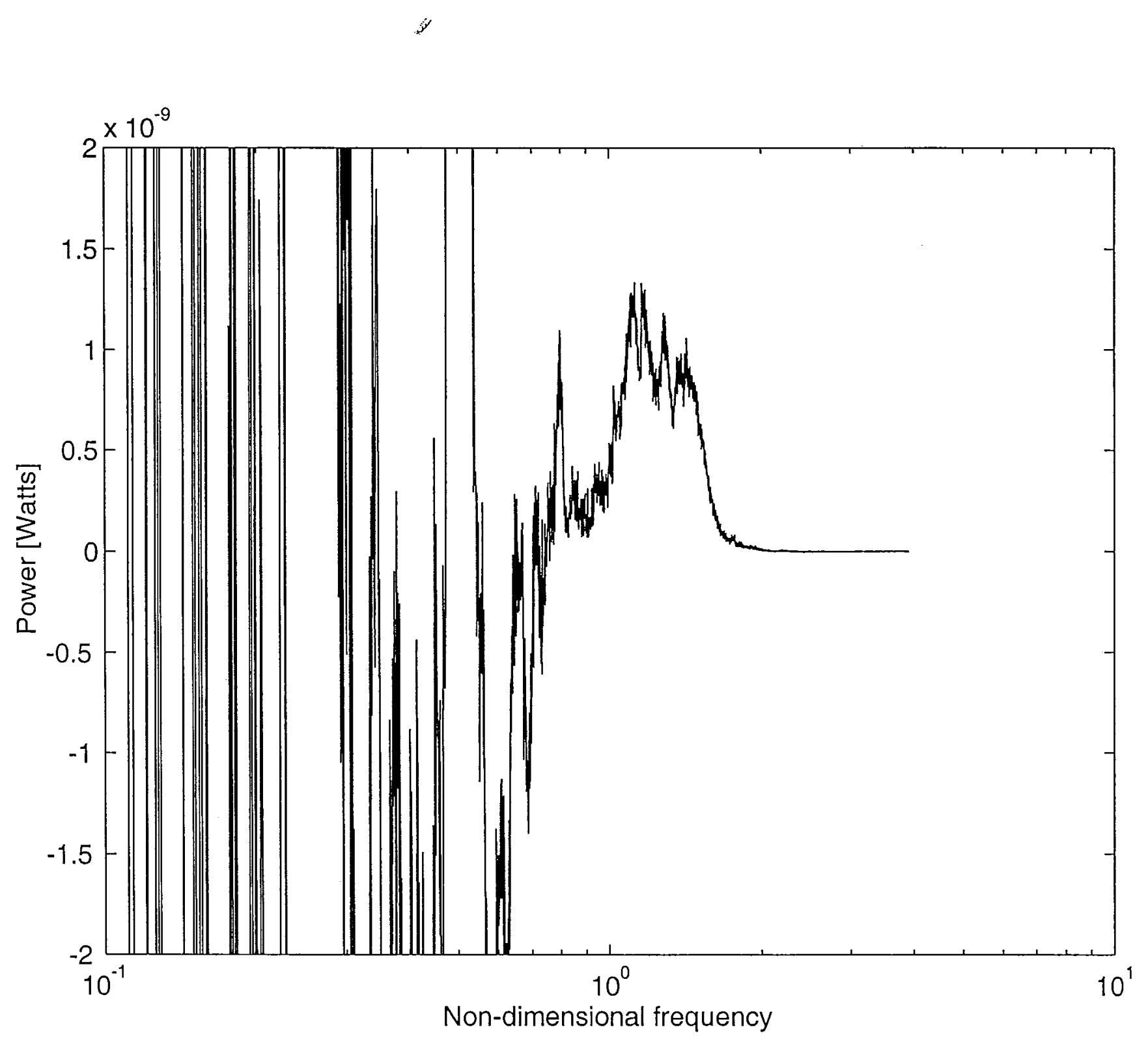


$F_{g} \|(c)$

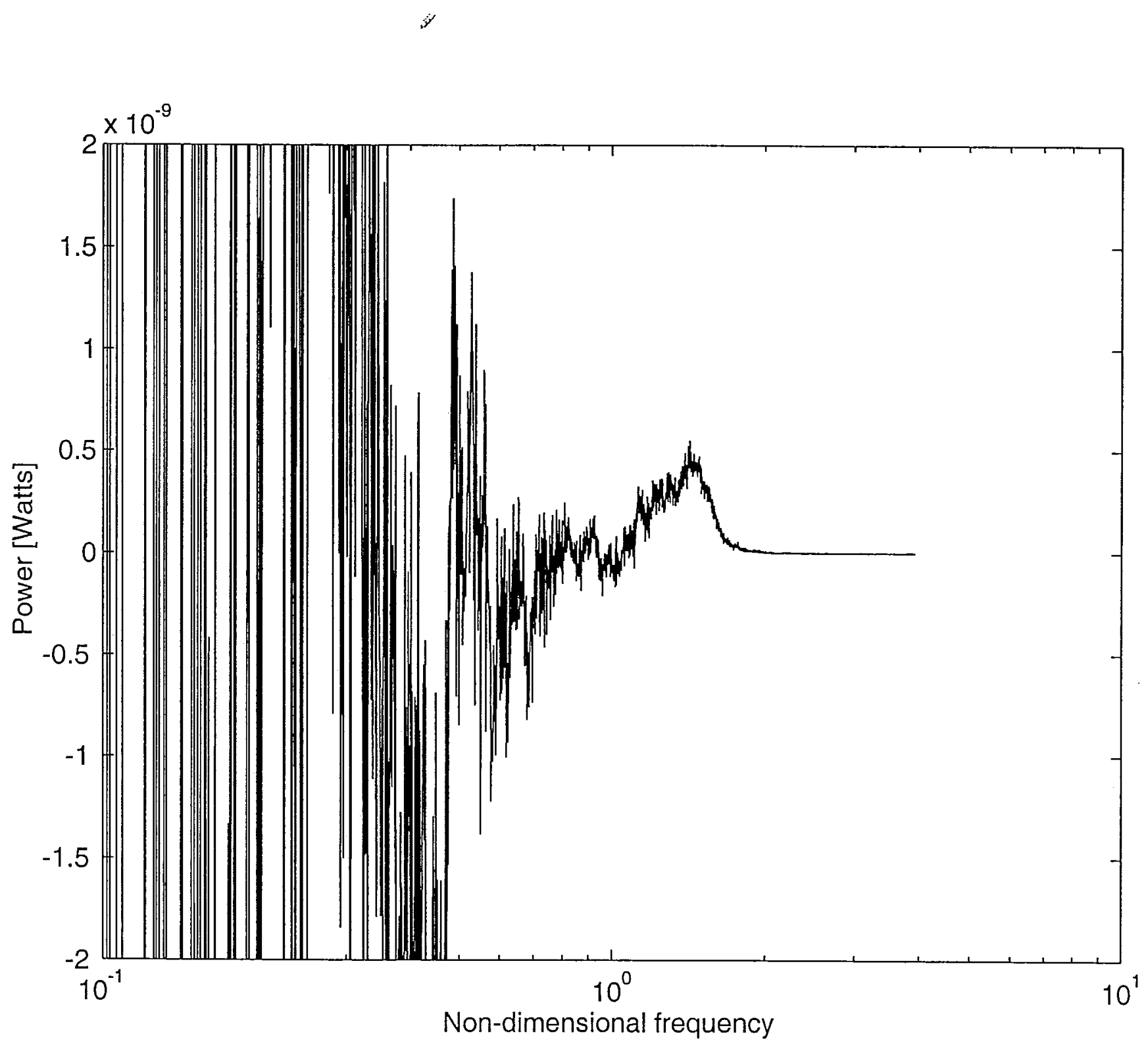


Fig $\|(d)$

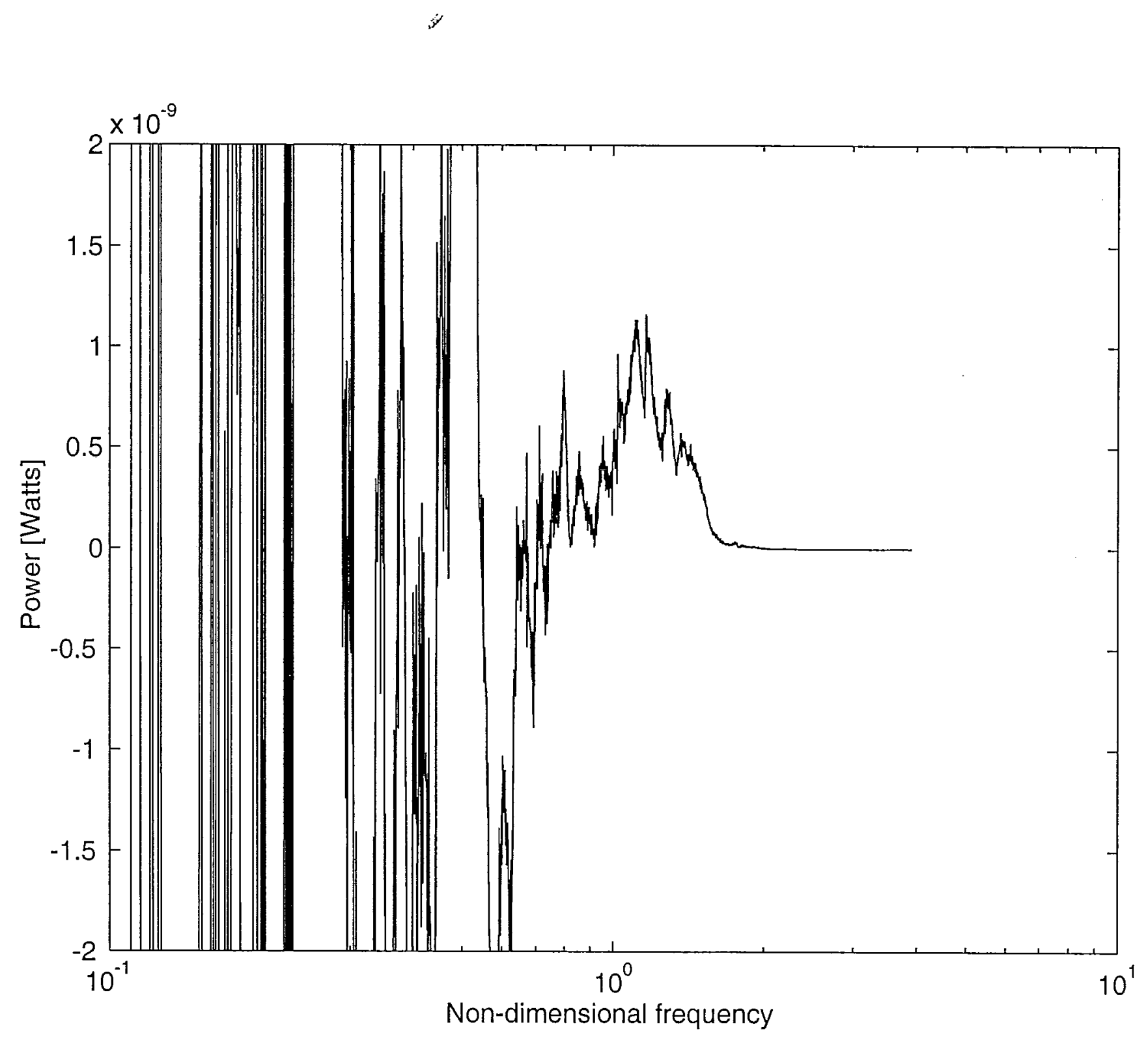


Fign(e)

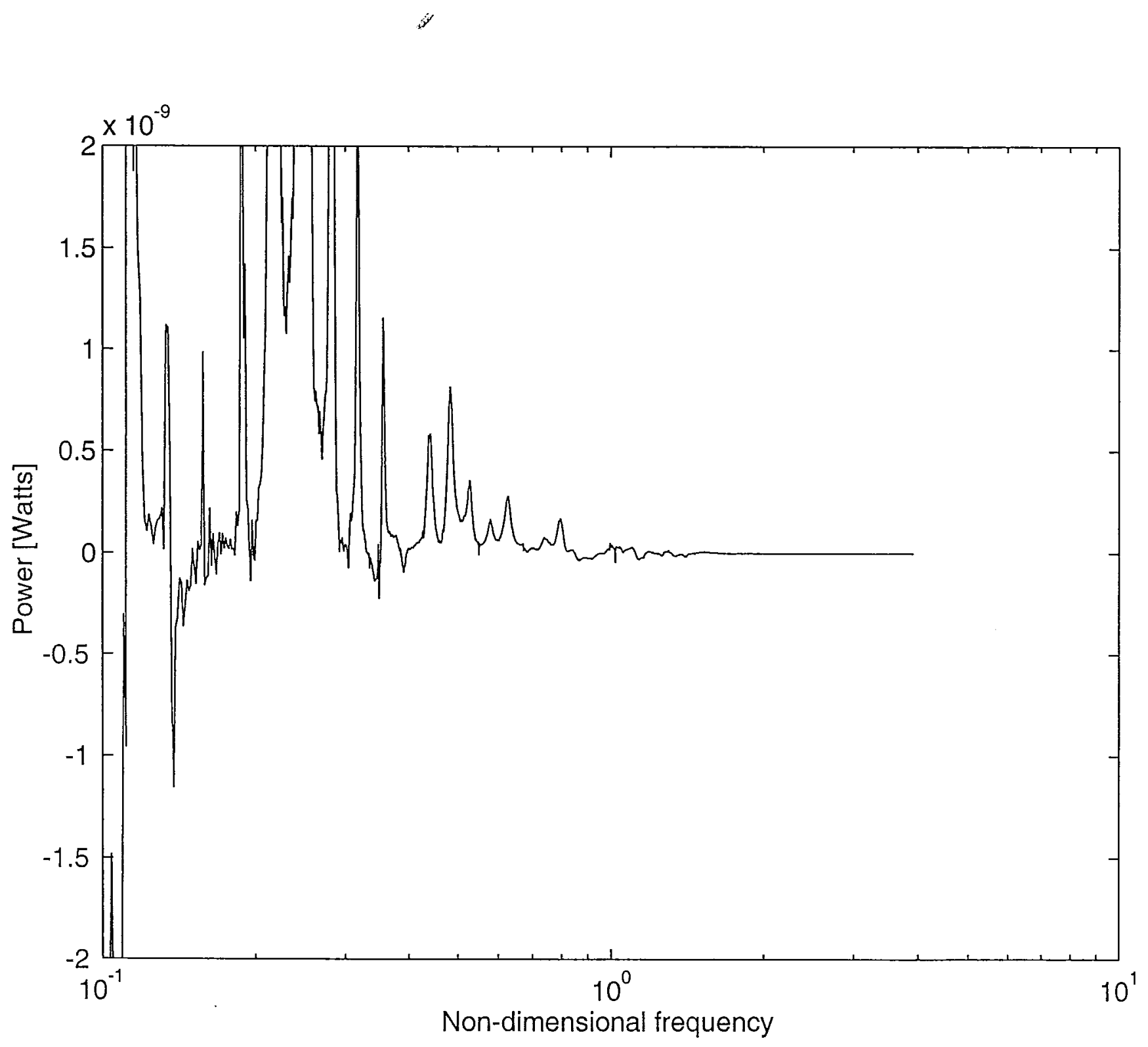


Fg 12

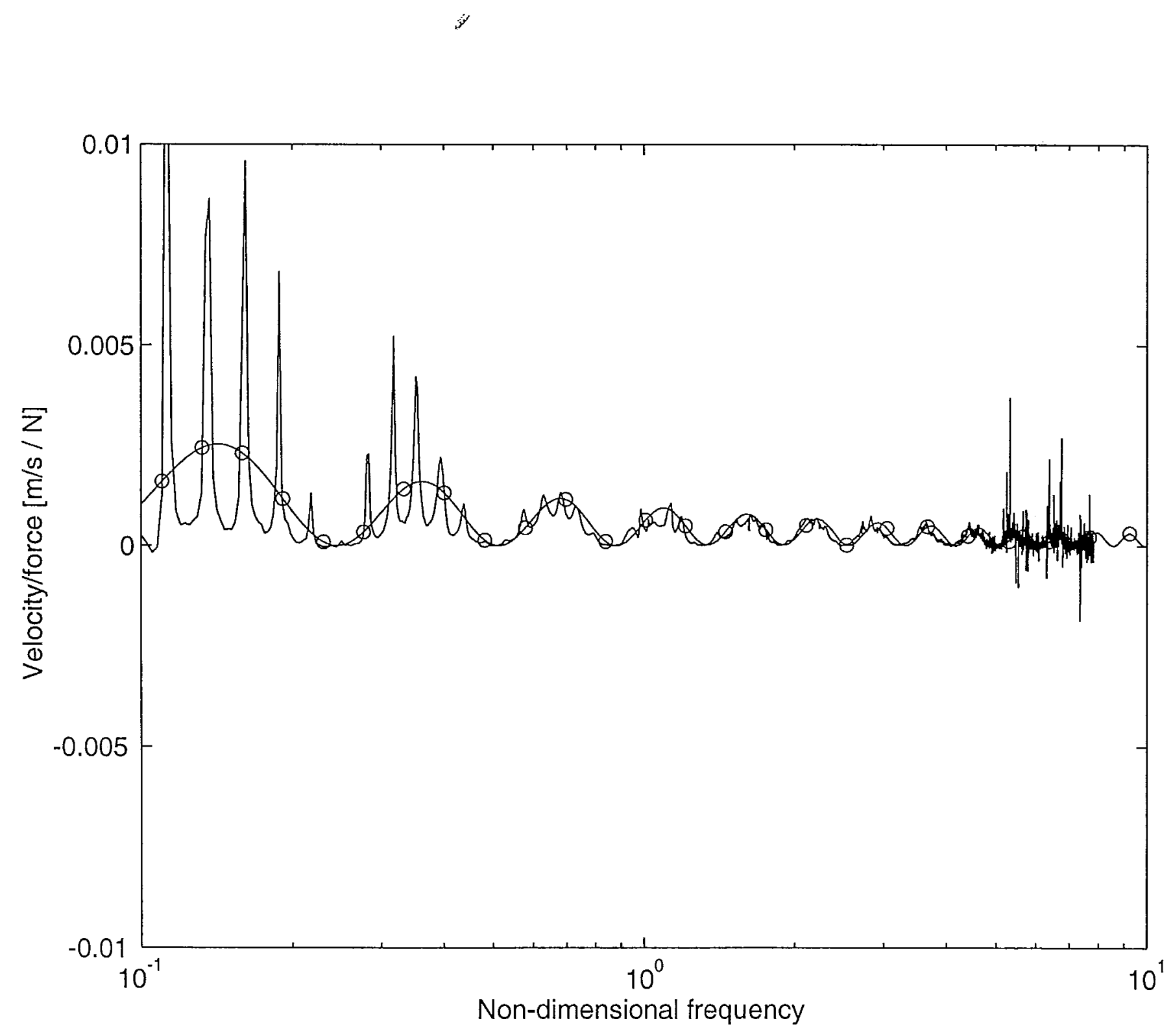


Fig is (a)

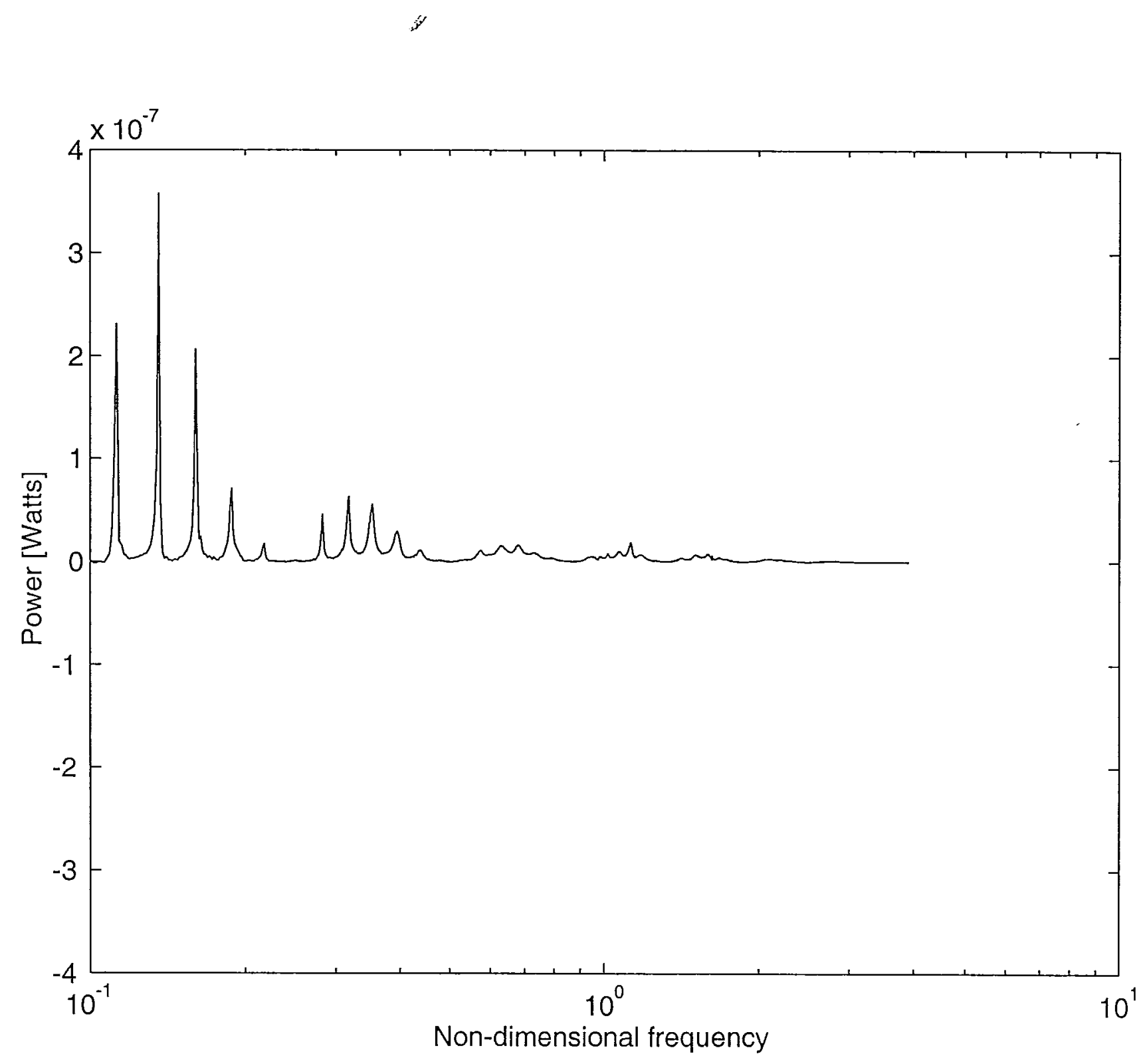


$F, g B(s)$

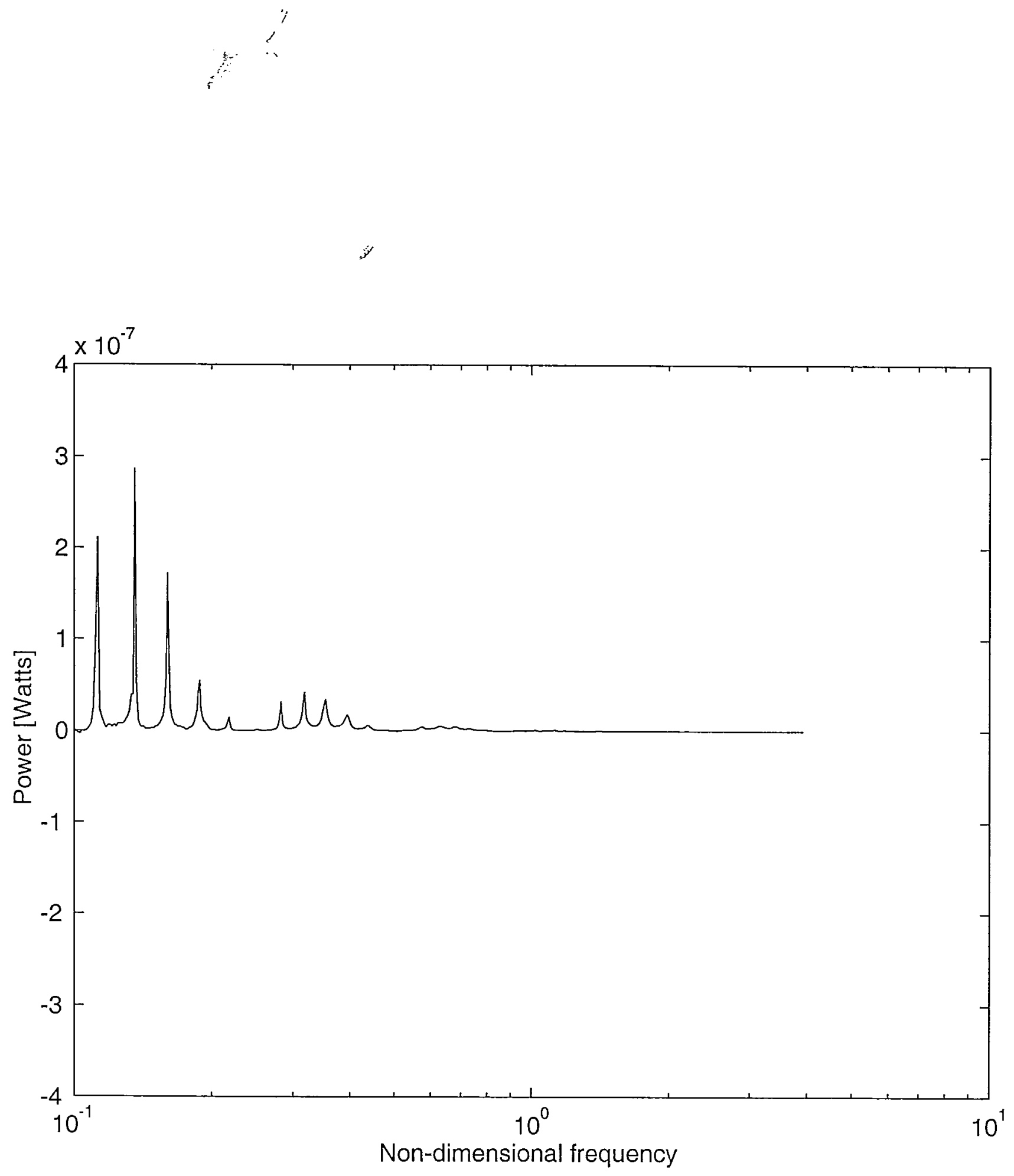


$F$ ig B (c)

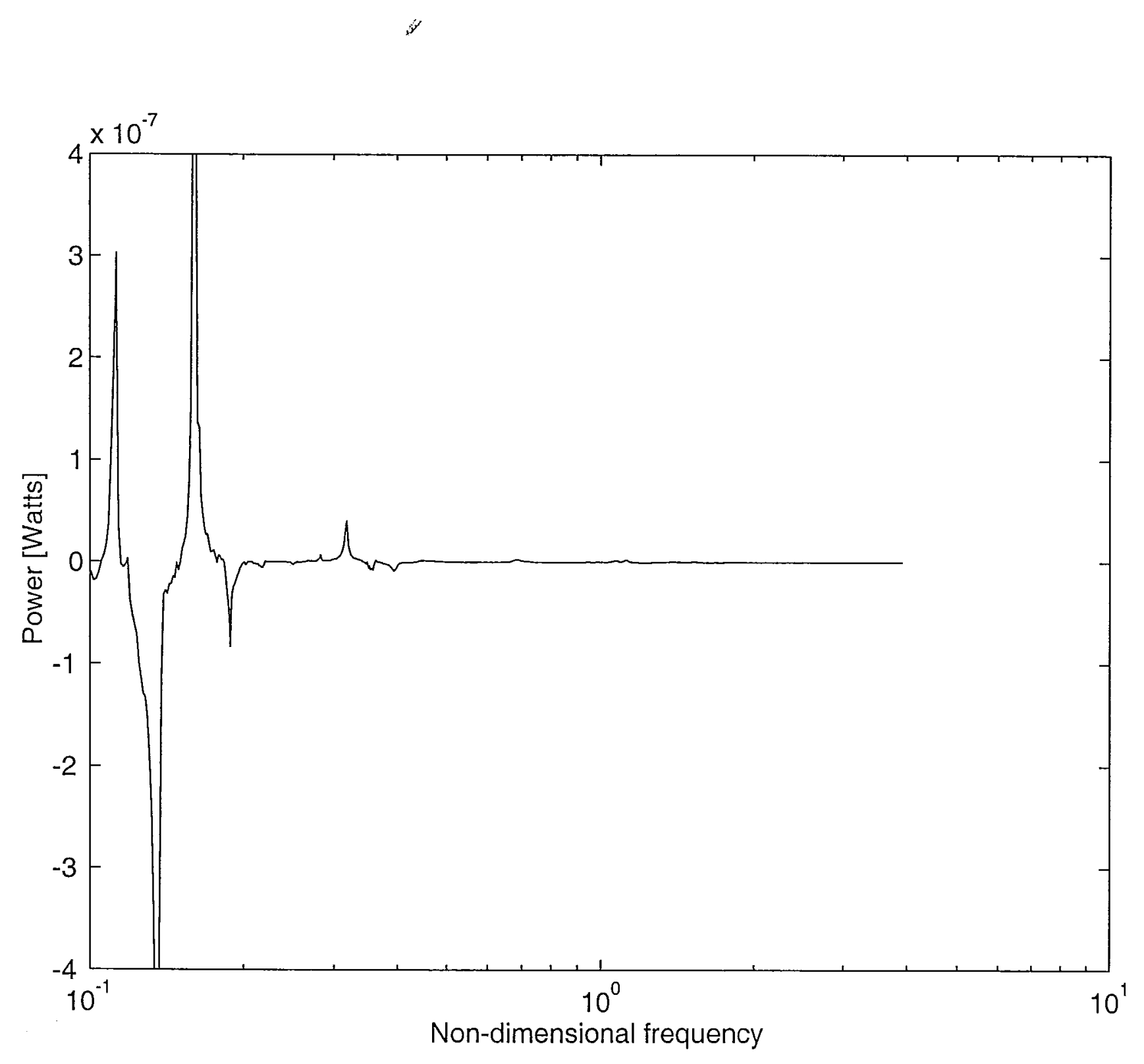


$F_{1 g} 13(d)$

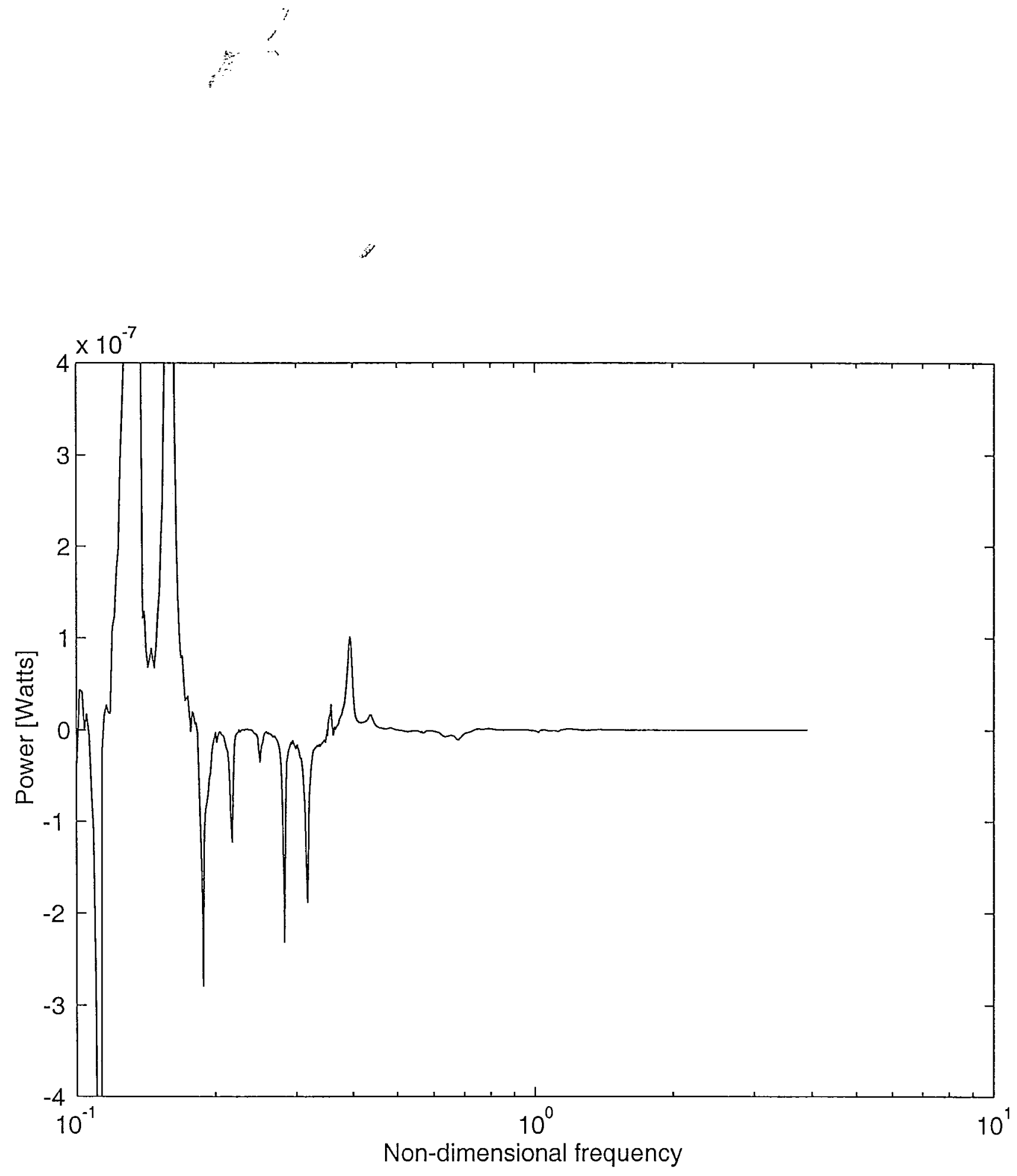


Fig $A 1$
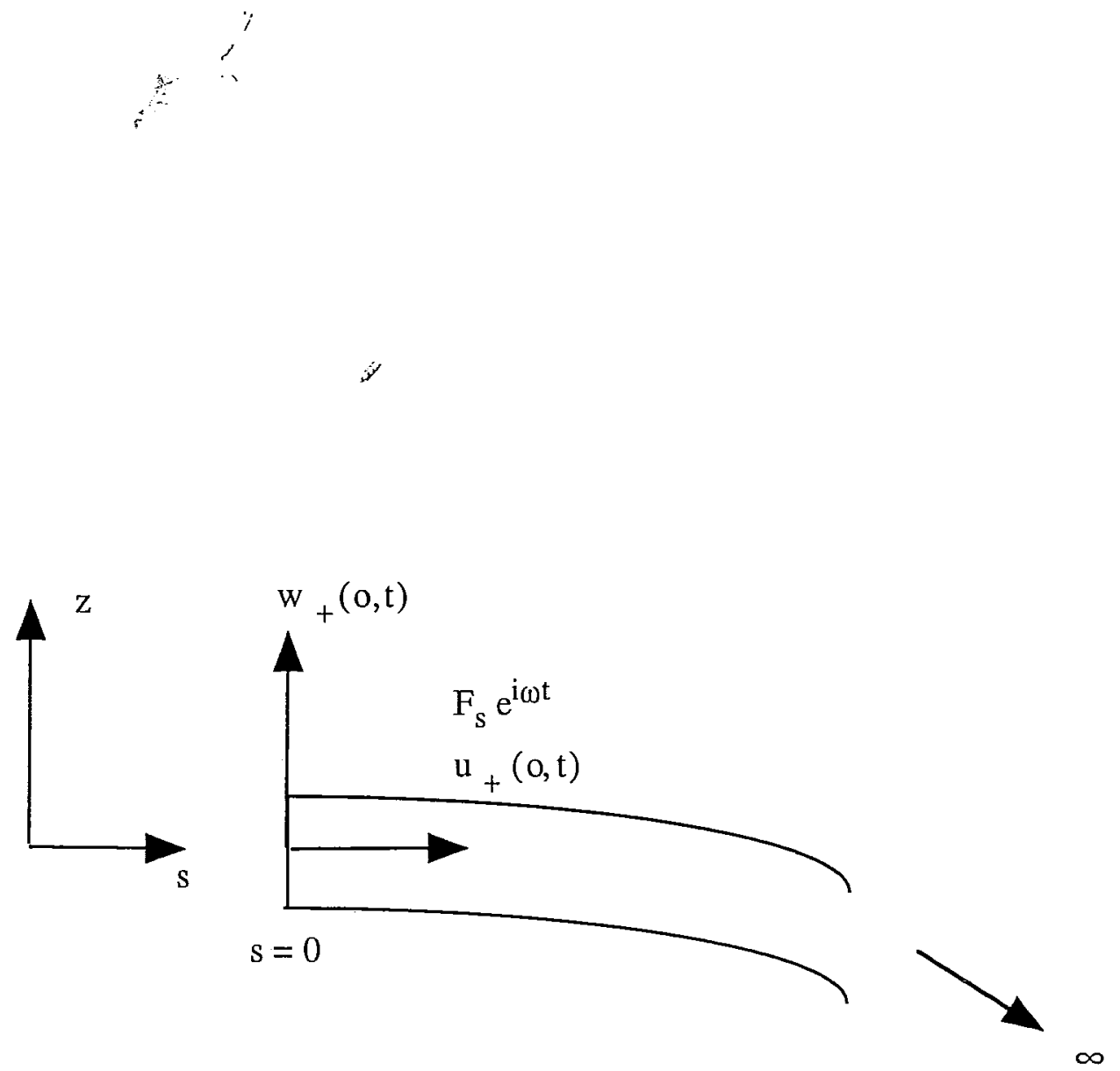
Fig A z
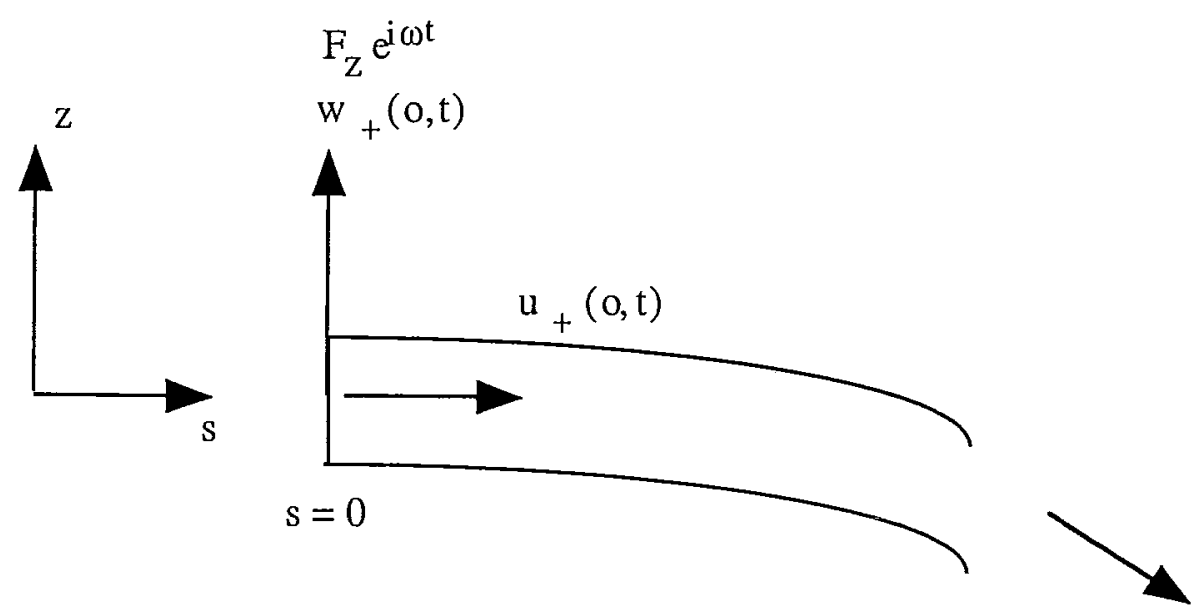

$\infty$ 
Fig $A_{3}$

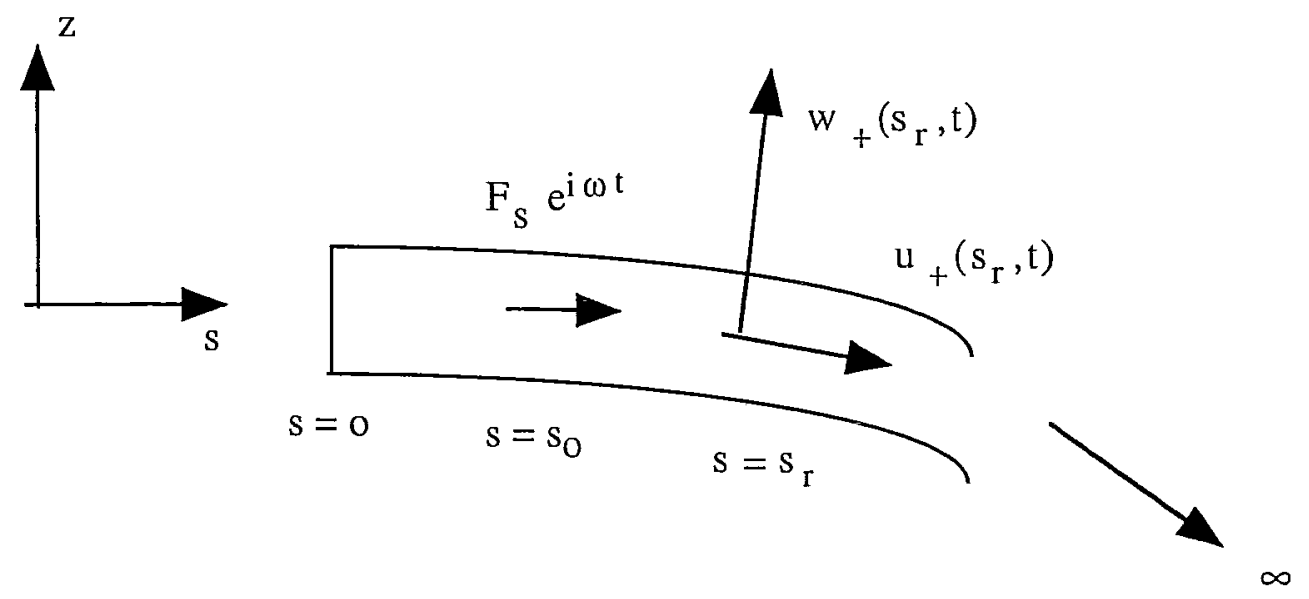


Fig $A_{4}$

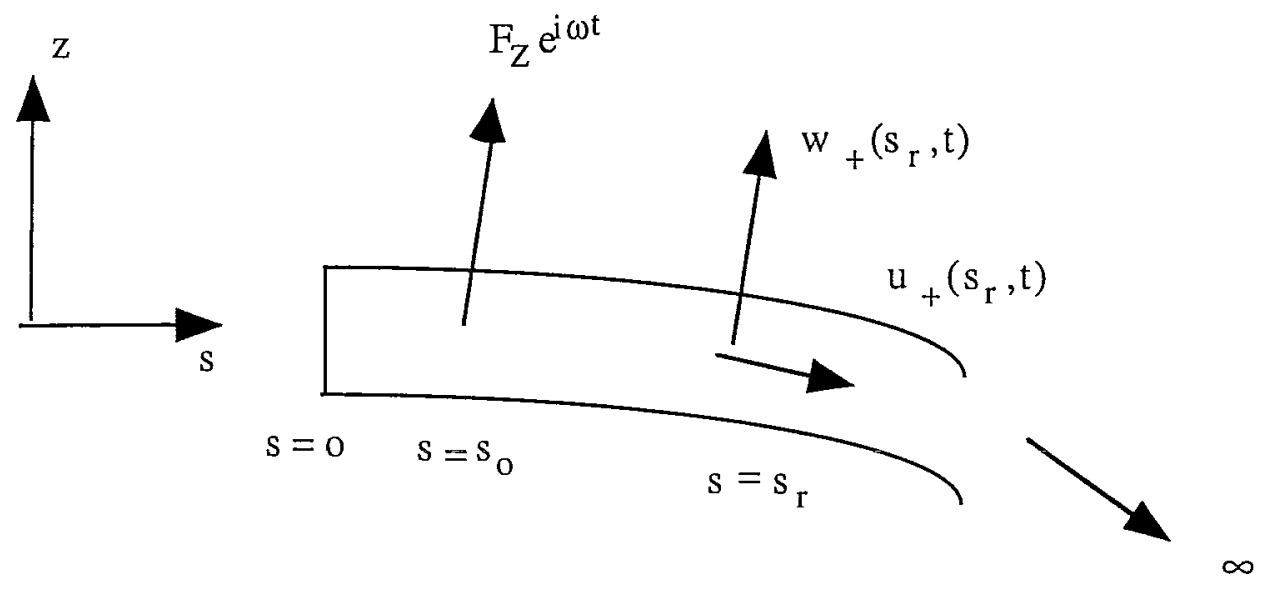

